\title{
Article \\ Numerical Design and Laboratory Testing of Encapsulated PCM Panels for PCM-Air Heat Exchangers
}

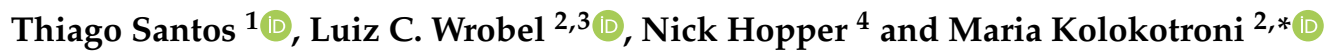 \\ 1 Federal Institute of Pernambuco, Rod. PE-60, km14, Ipojuca-PE 55590-000, Brazil; \\ thiagosantos@ipojuca.ifpe.edu.br \\ 2 Department of Mechanical and Aerospace Engineering, Brunel University London, Kingston Lane, \\ Uxbridge UB8 3PH, UK; luiz.wrobel@brunel.ac.uk \\ 3 Pontifical Catholic University of Rio de Janeiro (PUC-Rio), Rua Marquês de São Vicente 225, \\ Rio de Janeiro 22451-900, Brazil \\ 4 Monodraught Ltd., Halifax House, High Wycombe HP12 3SE, UK; nick.hopper@monodraught.co.uk \\ * Correspondence: maria.kolokotroni@brunel.ac.uk
}

Citation: Santos, T.; Wrobel, L.C.;

Hopper, N.; Kolokotroni, M.

Numerical Design and Laboratory Testing of Encapsulated PCM Panels for PCM-Air Heat Exchangers. Appl. Sci. 2021, 11, 676. https://doi.org/ 10.3390/app11020676

Received: 23 November 2020 Accepted: 6 January 2021

Published: 12 January 2021

Publisher's Note: MDPI stays neutral with regard to jurisdictional clai$\mathrm{ms}$ in published maps and institutional affiliations.

Copyright: (C) 2021 by the authors. Licensee MDPI, Basel, Switzerland. This article is an open access article distributed under the terms and conditions of the Creative Commons Attribution (CC BY) license (https:// creativecommons.org/licenses/by/ $4.0 /)$.

\begin{abstract}
Heat transfer between encapsulated PCM panels and air plays an important role in PCMAir heat exchangers. A new design for the encapsulation panel was developed considering practical aspects such as the cost of production and ease of manufacturing, in addition to heat transfer and pressure drop. A number of encapsulated panel surfaces were first investigated via 3D CFD simulations and compared with an existing panel in use by a commercial PCM-Air heat exchanger manufacturer. After validation, 2D CFD simulations were carried out for 32 different geometries to select the most effective design, which was fabricated and tested in the laboratory. Laboratory parameters tested included heat transfer, pressure drop and melting/solidifying. The laboratory results confirmed the improvements of the new panel in comparison with the existing panel and a flat panel. It was found that the proposed design doubled the heat transfer, holds $13.7 \%$ more material and the fan can overcome the increased pressure drop.
\end{abstract}

Keywords: PCM-Air heat exchanger; PCM encapsulation; phase change material; active LTES; enhanced heat transfer

\section{Introduction}

Ventilation systems with PCM-Air heat exchangers can offer cooling with a low energy consumption as only a fan is used. They use the principle of thermal storage through latent heat to cool a space in climatic regions where the ambient air temperature is not low enough to cool the space during the day but cool enough to charge the PCM during the night. The concept has been studied extensively [1-5] and its performance in practice evaluated [6-8].

Phase Change Materials in PCM-Air heat exchangers are commonly encapsulated in panels and stacked into a channel; this is usually termed as a thermal battery (TB). However, available panels are for general purposes and not specifically designed for ventilation heat exchangers. As a consequence, they have low heat transfer efficiency. Most research to-date on PCM-Air heat exchangers focusses on the PCM itself with only few on the improvement of the heat transfer on the air-side. Typically, PCMs have low thermal conductivity; thus, improvements in the heat transfer between air and panel will increase the overall performance of the system and lead to a fast thermal response, fast charging period and a reduction in energy consumption.

The most common techniques used to increase the heat transfer over a channel are to modify the channel surface to include obstructions in the form of ridges, fins, dimples and grooves. Figure 1 shows diagrammatically the obstructions discussed based on literature findings. 


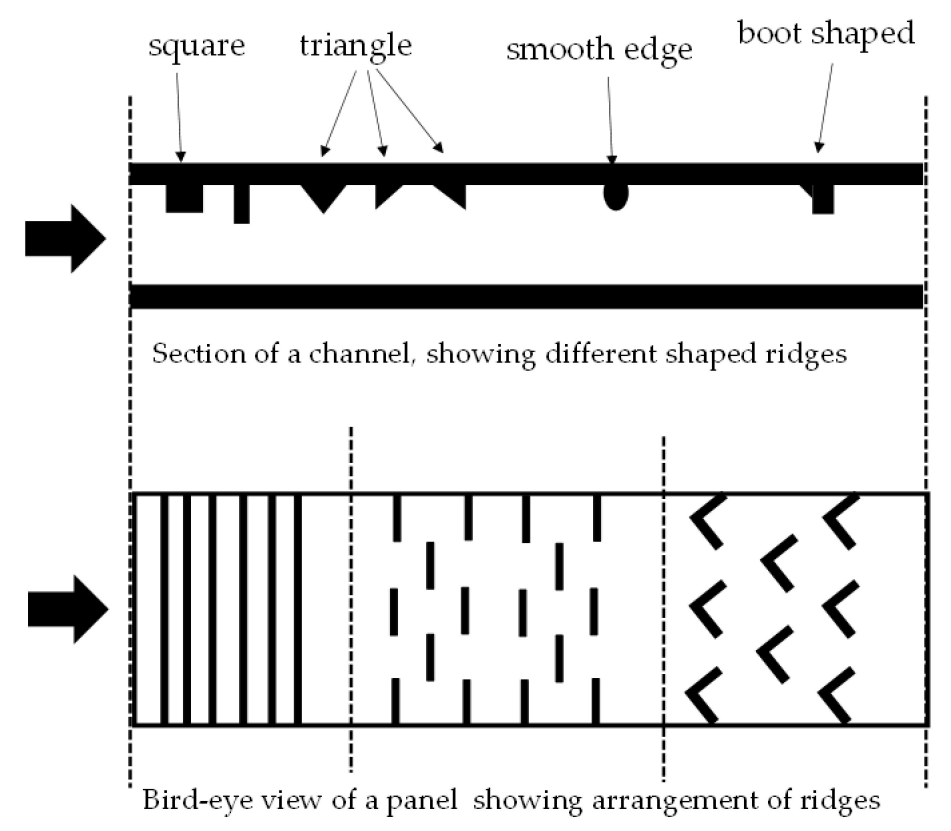

Figure 1. Section and bird-eye view of a channel showing various obstructions and their arrangement (not in scale).

Moon [9] analysed sixteen ridge shapes with different geometries by varying pitch ratio through CFD simulations. The performance was analyzed using the Nusselt Number and friction loss and a strong relationship was shown with the cross-sectional rib shape. A boot shaped ridge presented the best results in terms of heat transfer, with a pressure drop similar to a square ridge for Reynolds number between 5000 and 50,000. Yang et al. [10] introduced symmetric and staggered squared high ridges in channels on the bottom and the top of rectangular channel walls. The results, validated by experiments, showed that a larger blockage ratio corresponds to a higher heat transfer and friction factor. The symmetric arrangement and higher blockage increased $N u / N u_{0}$ in the range of 6-7 and the staggered arrangement and higher blockage by 3.5. Conversely, a higher friction factor increases pressure drop thus increasing energy consumption as it demands more power from the fan. To reduce pressure drop, Tanda [11] suggested to break down the ribs and position them in various orientations. The surface temperature was recorded by a charged coupled device (CCD) video camera in order to obtain a detailed distribution of the heat transfer coefficient over the heat transfer surface. The study analyzed transverse integral and broken ribs and a V-shaped broken rib $\left(\right.$ at $45^{\circ}$ and $60^{\circ}$ ) with three different pitch-to-height ratios. Results showed the highest $N u / N u_{o}$ for transverse broken ribs with pitch-to-height of four variations in the range of (3.2-2.4), followed by a transverse pitch-to-height of 8 and a V shaped rib for a $R e=8900-36,000$. Kim et al. [12] studied the effect of angled rib turbulators in a double-side wall cooling channel at $R e=10,000$. Results obtained through simulations found an optimized value of Nusselt ratio of 2.9 at $53.41^{\circ}$ for a simulated range from $30^{\circ}$ to $80^{\circ}$. Alternatively, protrusions and grooves can be combined. Zhang et al. [13] compared the heat transfer in a channel with a single-wall composed by one upstream rib and one downstream groove, with one upstream protrusion in three different positions in a channel and one downstream groove and three upstream protrusions in parallel followed by one groove. The result shows that parallel protrusions upstream to grooves perform better $\left(R e=5000, \frac{N u}{N o_{0}}=1.40 ; R e=20,000, \frac{N u}{N o_{0}} \cong 1.44\right)$ than other cases $\left(R e=5000, \frac{\mathrm{Nu}}{\mathrm{No}} \cong 1.35 ; R e=20,000, \frac{\mathrm{Nu}}{\mathrm{N} u_{0}} \cong 1.3-1.32\right)$ with an increase in the average Nusselt number ratio when the Reynolds number increases.

Promvonge and Thianpong [14] experimented with four different shaped ridges: wedge pointing upstream, wedge pointing downstream, triangular and rectangular ridge staggered and in-line over a turbulent channel $(R e=4000-16,000)$. The result shows im- 
provements in heat transfer compared to a smooth channel where the wedge downstream in-line produced the best performance in terms of Nusselt number ratio $\left(N u / N u_{0} \cong 4.4\right)$ and the rectangular $\left(\mathrm{Nu} / \mathrm{Nu} u_{0} \cong 3.7\right)$ was the worst. When pressure drop is taken into account, the triangular staggered channel has the best thermal performance $\left(\eta=\left(\frac{N u}{N u_{o}}\right) /\left(\frac{\Delta p}{\Delta p_{o}}\right)^{1 / 3} \cong 1-1.1\right)$ followed by triangular in-line and staggered upstream wedge. Following from the previous study, Thianpong et al. [15] experimentally studied different heights of triangular ridges staggered and in-line through a constant heat-flux channel for Reynolds number from 5000 to 22,000. The result shows an increase of approximately 1.8-4 in terms of Nusselt number when compared to a smooth channel, and a variation of thermal performance up to 1.3. The studies presented above confirm that the inclusion of ridges over a channel is an efficient solution to enhance the heat transfer. They also suggest that rounded ridges are preferred due to a smaller increase in pressure drop when compared to other ridges; they also incur lower cost of production. To evaluate, validate and also understand the impact of simplifications made during the numerical simulation process, laboratory tests are imperative.

The experiments commonly used by researchers to evaluate heat transfer due to heat transfer augmentation use thermocouples [14,16,17], infrared cameras [10,18-21] and CCD cameras with a thermochromic liquid crystal layer or a colour processing system $[11,22,23]$. The first uses thermocouples before and after the channel to evaluate the overall heat transfer with different ridges. Furthermore, thermocouples were fitted on channels surface to measure temperature distribution on the wall, ensure the steady state of the test and calculate the heat of convection. In cases that the local Nusselt number field is important, an infrared or a CCD camera allows a better understanding of the heat exchange. This was confirmed by Yang et al. [10]. His infrared camera experiment and CFD simulations showed the importance of the separation and reattachment region and also shown a higher increase of heat transfer effectiveness at laminar flow rate.

Most researchers focus on the improvement of heat transfer in the channel and pressure drop by the panel and literature findings have informed the shapes examined and presented in this paper. However, practical considerations such as cost of production, rigidity and ease of manufacturing would improve the uptake of the proposed design and therefore these are also considered for the final recommendation. This paper focuses on the development, fabrication and validation of a new panel design considering five key performance indicators (KPIs) (a) heat transfer, (b) pressure drop, (c) rigidity, (d) cost of production and (e) ease of manufacturing. Laboratory testing used thermocouples because the focus is on the overall performance of the panel rather than the localized effects.

\section{Methods}

\subsection{Design Procedure}

The design method used CFD simulations (ANSYS Fluent) assuming a steady state condition, incompressible and constant air properties (at $300 \mathrm{~K}$ ), and fully developed flow. Figure 2 shows the steps of the design from concept to fabrication. The steps were the following:

- Initially, a set of twelve 3D designs were simulated based on literature findings on the shape of ridges, their dimensions and separation; more details are included in Section 2.1.1. Correlations and a laboratory test were used to validate the simulation; this is presented in Section 2.1.2. One design was selected as the most promising which is uniform along its width.

- 2D CFD simulations were carried out for 21 different geometries using a two-step approach. First, one panel was simulated in order to find the optimum panel dimensions (based on the five KPIs). Secondly, a refinement was carried out to select the optimum spacing between panels and the thickness of the panel. This is described in Section 2.1.3.

- $\quad$ Finally, the most promising panel was fabricated and further tested in the laboratory. 
- $\quad$ Figure 2 presents some details of the panels. The dimensions presented on the right side show the radius, distance between ridges, panel thickness and height of the ridges used for the 2D simulations. These dimensions are represented as ratios with panel length, panel width, duct height and air gap with more design details shown in Tables 1 and 2. Figure 3 presents the control volume, the boundary conditions and the dimensions used.

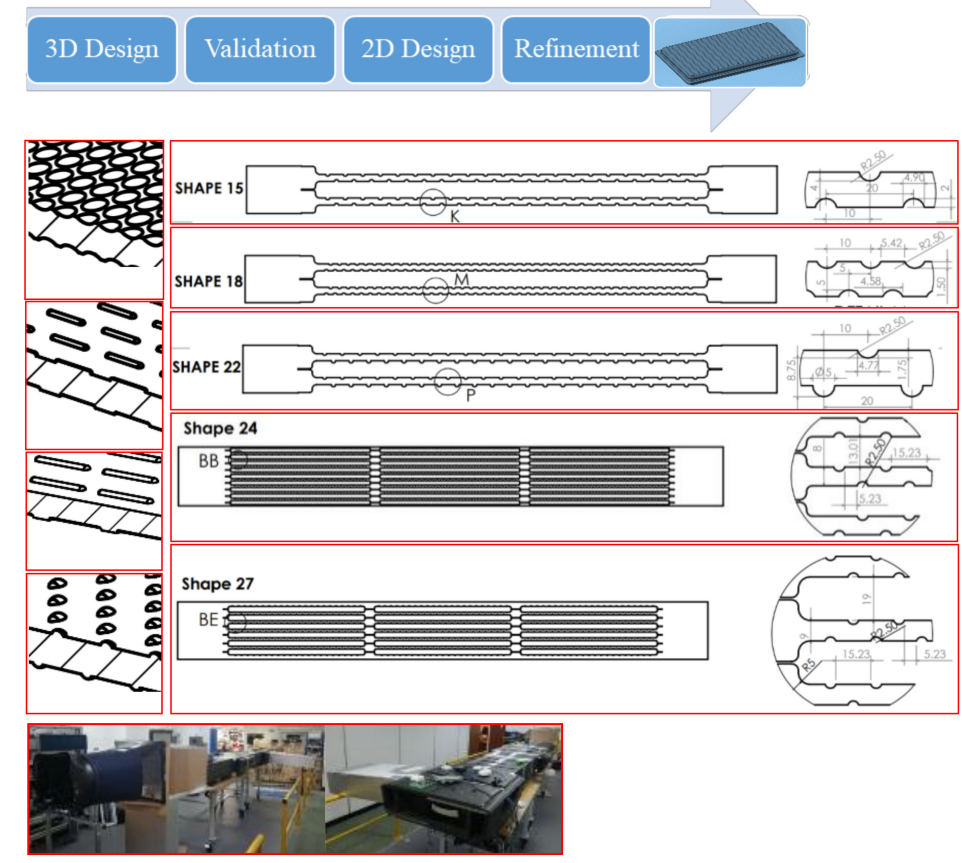

Figure 2. Design procedure with some designs used.

Table 1. Modelled geometrical variations of the panel for 3D cases.

\begin{tabular}{ccccc}
\hline Shape & $\begin{array}{c}\text { 3D Simulations } \\
\text { Ridge Height/ } \\
\text { Air Gap (e/h) }\end{array}$ & $\begin{array}{c}\text { Ridge Pitch } \\
\text { Length/Panel } \\
\text { Length (s/l) }\end{array}$ & $\begin{array}{c}\text { Ridge Width/ } \\
\text { Panel Width } \\
\left.\text { ( } \mathbf{w}_{\mathbf{r}} / \mathbf{w}\right)\end{array}$ & $\begin{array}{c}\text { Ridge Radius (r) } \\
\text { (mm) }\end{array}$ \\
\hline Shape 0 dimpled & 0.250 & 0.058 & 0.033 & 6 \\
\hline Shape 1 & 0.188 & 0.039 & 0.077 & 1.5 \\
\hline Shape 2 & 0.188 & 0.039 & 0.083 & 1.5 \\
\hline Shape 3 & 0.313 & 0.039 & 0.083 & 2.5 \\
\hline Shape 4 & 0.125 & 0.039 & 0.077 & 1.5 \\
\hline Shape 5 & 0.313 & 0.078 & 0.183 & 2.5 \\
\hline Shape 6 & 0.250 & 0.039 & 0.093 & 5 \\
\hline Shape 7 & 0.250 & 0.062 & 0.867 & 5 \\
\hline Shape 8 teardrop & 0.313 & 0.039 & 0.029 & 2.5 \\
\hline Shape 9 & 0.219 & 0.044 & 0.867 & 2.5 \\
\hline Shape 10 & 0.313 & 0.056 & 0.867 & - \\
\hline Existing & 0.125 & 0.033 & 0.033 & \\
\hline
\end{tabular}


Table 2. Modelled geometrical variations of the panel for 2D cases.

\begin{tabular}{|c|c|c|c|}
\hline \multicolumn{4}{|c|}{ 2D Simulation of Shape 9} \\
\hline Shape 9 Variations & $\begin{array}{l}\text { Ridge Height/Panel } \\
\text { Length (s/1) }\end{array}$ & $\begin{array}{l}\text { Ridge Pitch/Panel } \\
\text { Length (s/1) }\end{array}$ & $\begin{array}{c}\text { Ridge Radius (r) } \\
(\mathrm{mm})\end{array}$ \\
\hline Shape 11 & 0.219 & 0.044 & 2.5 \\
\hline Shape 12 & 0.063 & 0.022 & 7.5 \\
\hline Shape 13 & 0.063 & 0.022 & 7.5 \\
\hline Shape 14 & 0.188 & 0.044 & 2.5 \\
\hline Shape 15 & 0.250 & 0.044 & 2.5 \\
\hline Shape 17 & 0.188 & 0.033 & 2.5 \\
\hline Shape 18 & 0.188 & 0.022 & 2.5 \\
\hline Shape 19 & 0.219 & 0.044 & 2.5 \\
\hline Shape 20 & 0.219 & 0.056 & 2.5 \\
\hline Shape 21 & 0.281 & 0.044 & 3.0 \\
\hline Shape 22 & 0.219 & 0.044 & 2.5 \\
\hline Shape 23 & 0.281 & 0.044 & 2.5 \\
\hline \multicolumn{4}{|c|}{ 2D Simulation Refinement } \\
\hline Shape 9 in Module & $\begin{array}{c}\text { Gap between } \\
\text { panels/Panels Duct } \\
\text { Height }(\mathrm{h} / \mathrm{H})\end{array}$ & $\begin{array}{c}\text { Panel } \\
\text { Thickness/Duct } \\
\text { Height }(\mathrm{h} / \mathrm{H})\end{array}$ & $\begin{array}{l}\text { Number of Panels } \\
\text { (p) }\end{array}$ \\
\hline Shape 24 & 0.042 & 0.069 & 9 \\
\hline Shape 25 & 0.042 & 0.079 & 8 \\
\hline Shape 26 & 0.042 & 0.124 & 6 \\
\hline Shape 27 & 0.048 & 0.101 & 6 \\
\hline Shape 28 & 0.053 & 0.101 & 6 \\
\hline Shape 29 & 0.063 & 0.121 & 5 \\
\hline Shape 30 & 0.051 & 0.151 & 4 \\
\hline Shape 31 & 0.034 & 0.080 & 8 \\
\hline Shape 32 & 0.030 & 0.070 & 9 \\
\hline
\end{tabular}

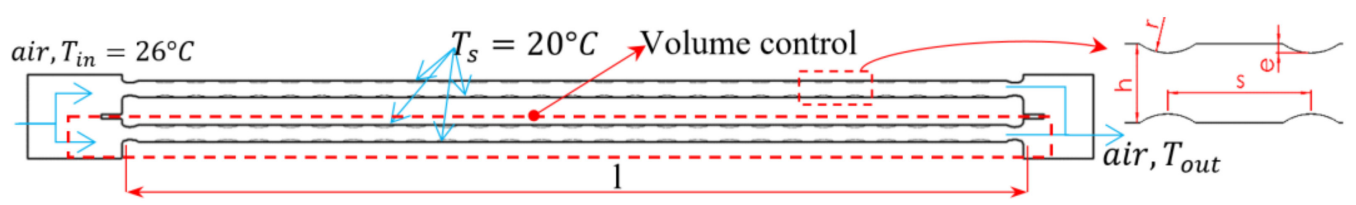

Figure 3. PCM panel control volume (r: radius; e: ridge height; s: spacing between ridges; h: distance between panels (air gap)).

\subsubsection{D Simulations}

Nine 3D designs were generated (Figure 4, shapes 1-7 and 9-10) and compared with a hemispherical (shape 0), a teardrop (shape 8) and the existing panel. Each design was drawn with different rounded lozenges, protrusion and groove radius based on literature suggestions. All geometries vary by height and pitch, ridge pitch length, ridge pitch width, ridge radius (Table 1). For the CFD simulations the surface temperature was fixed at $20^{\circ} \mathrm{C}$ because it is a common melting point for PCMs used for this application. The inlet channel temperature was set as $26^{\circ} \mathrm{C}$ because this is a common value for the return air through recirculation or the outside air during cooling periods. The Reynolds number of 18,736 (which is equivalent of $130 \mathrm{~L} / \mathrm{s}$ ) for all cases was used as it represents the average 
airflow during the charging period. The distance between panels were the same as the existing configuration. The range of variation was based on the following: (i) Ridge height per airgap [0.125 $<e / h<0.313]$ : With the air gap between panels fixed, the height was augmented until the pressure drop considerably increased; (ii) Ridge pitch length $[0.033<s / l<0.078]$ : The number of ridges added per length (lines of ridges) were limited by the cost of production and ease of manufacturing; (iii) Ridge pitch width $\left[0.033<w_{r} / w<0.867\right]$ : The ridges added per width were limited by the cost of production and ease of manufacturing; and (iv) Ridge radius [1.5 $<r<6$ ]: The range of radius was limited by the cost of production, pressure drop and ease of manufacturing.

\subsubsection{Numerical Validation}

To ensure that the correct numerical model was selected, a smooth panel section was designed $(0.0422 \times 0.027 \times 0.575 \mathrm{~m})$ to evaluate the Nusselt number and compare with Gnielinski's correlation (Equation (1)) for smooth channels. The mesh was adapted through ANSYS Fluent until no changes on the fourth decimal were found on outlet pressure and outlet temperature. Added to that, under-relaxation factors were adjusted to allow convergence. The simulation stopped when the residual achieved $10^{-5}$ for turbulence, energy and continuity. Realizable $k-\varepsilon$ turbulence model with scalable near wall treatment functions and SIMPLE method for pressure-velocity coupling was used with second-order upwind scheme for pressure, momentum, turbulence and energy.

$$
\mathrm{Nu}_{\mathrm{D}}=\frac{\left(\frac{\mathrm{f}}{8}\right)\left(\operatorname{Re}_{\mathrm{D}}-1000\right) \operatorname{Pr}}{1+12.7\left(\frac{\mathrm{f}}{8}\right)^{\frac{1}{2}}\left(\operatorname{Pr}^{\frac{2}{3}}-1\right)}
$$

where $\mathbf{R e}$ is the Reynolds number, $\mathbf{P r}$ is the Prandtl number of the air and $\mathbf{f}$ is the friction factor calculated by the Petukhov correlation Equation (2):

$$
\mathbf{f}=\left(0.79 \ln \left(\operatorname{Re}_{\mathrm{Dh}}\right)-1.64\right)^{-2}
$$

After several iterations, the final mesh of the panel section had 2,389,901 nodes with results presenting a difference of $5.41 \%$ between Gnielinski's correlation and simulation.

Moreover, a laboratory test (Figure 5) using the existing panel with 1,2 and 3 modules measured and analyzed the pressure drop along the channel to validate the CFD numerical model. Measurements were made upstream and downstream of the thermal battery modules using the Tchebycheff's method [24] with the Pitot tube TSI TA465-P.

Three different Reynolds numbers $(10,089,18,736$ and 21,600$)$ were set for a twomodule TB and two Reynolds numbers $(18,736$ and 21,600$)$ for one and three TB modules. For the CFD simulation, the mesh followed the same criteria used to generate the smooth panel in 2D. As the existing panel is not uniform along its width, a section located at the top of the bulges was selected to perform the 2D analysis. Table 3 shows the number of nodes and elements.

Table 3. Number of nodes and elements before and after adaptive meshing.

\begin{tabular}{ccccc}
\hline \multirow{2}{*}{ Shapes } & \multicolumn{2}{c}{ First Mesh } & \multicolumn{2}{c}{ Adapted Mesh } \\
\cline { 2 - 5 } & Nodes & Elements & Nodes & Elements \\
\hline 1 module & 168,489 & 158,948 & 371,043 & 330,158 \\
2 modules & 265,665 & 248,554 & $1,083,181$ & 982,672 \\
3 modules & 272,987 & 252,044 & $1,395,533$ & $1,202,846$ \\
\hline
\end{tabular}



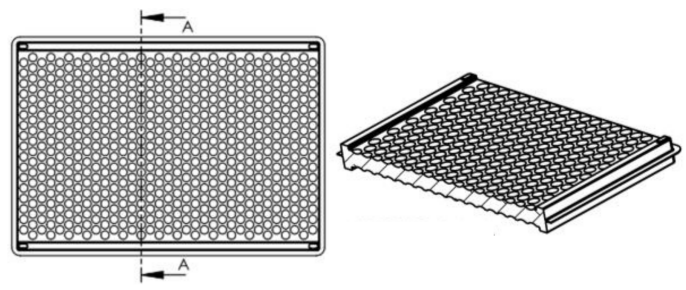

Shape 0

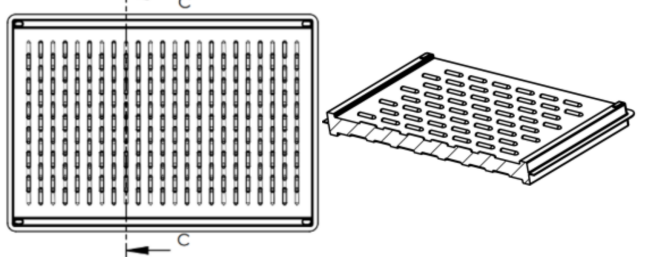

Shape 2

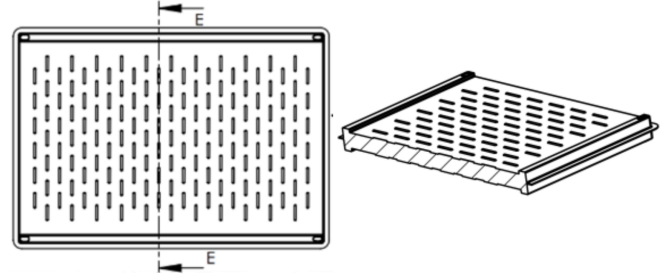

Shape 4

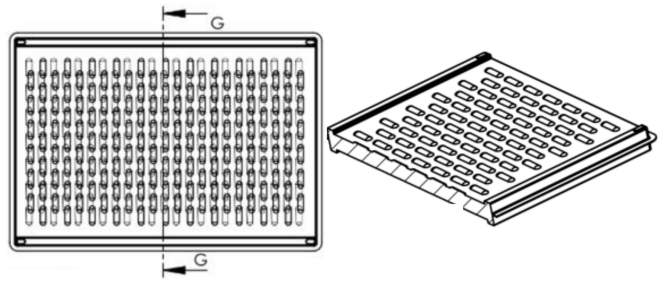

Shape 6

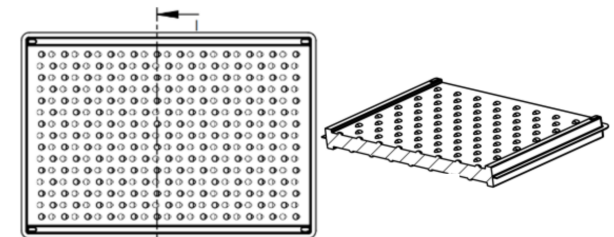

Shape 8

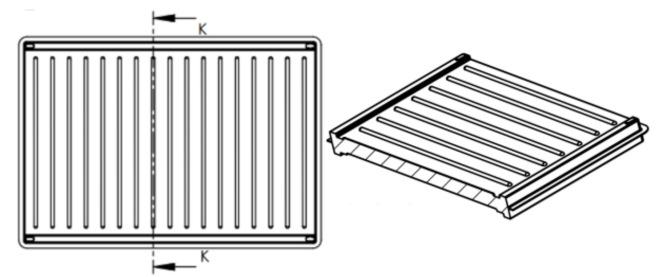

Shape 10

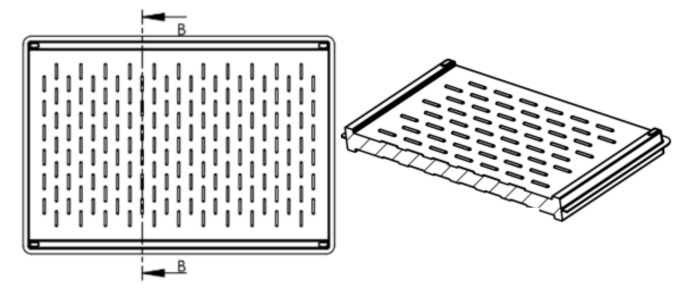

Shape 1

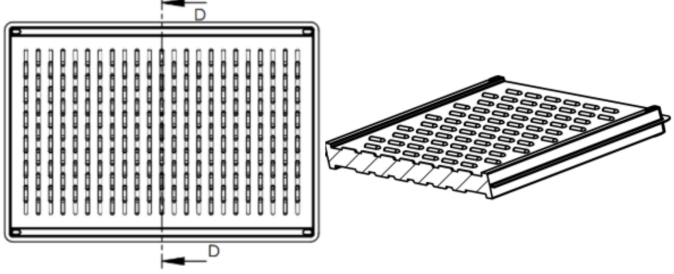

Shape 3

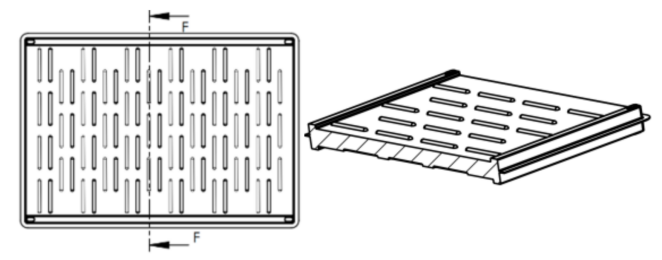

Shape 5

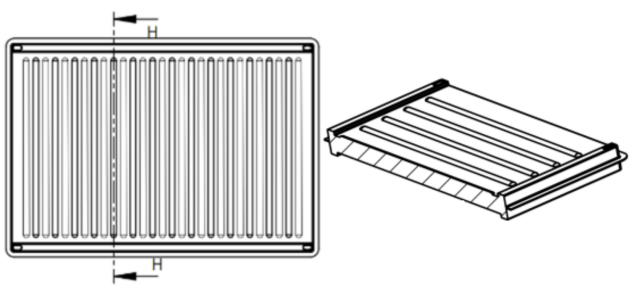

Shape 7
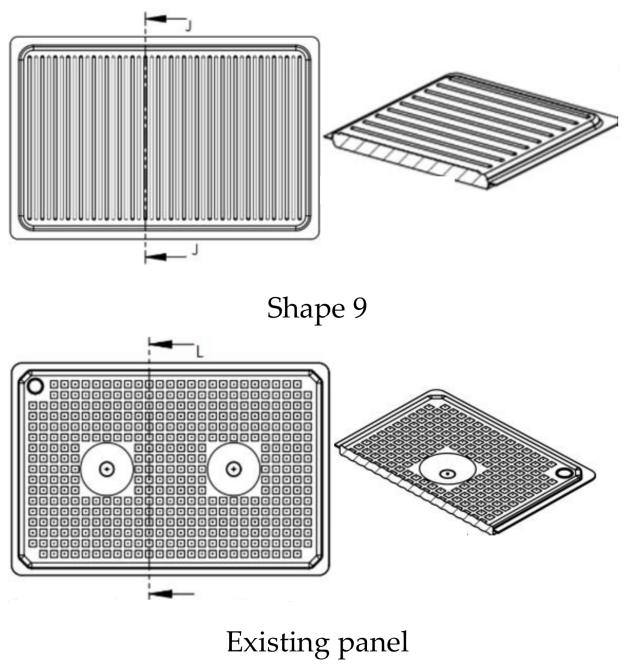

Figure 4. 3D models cut sections. 

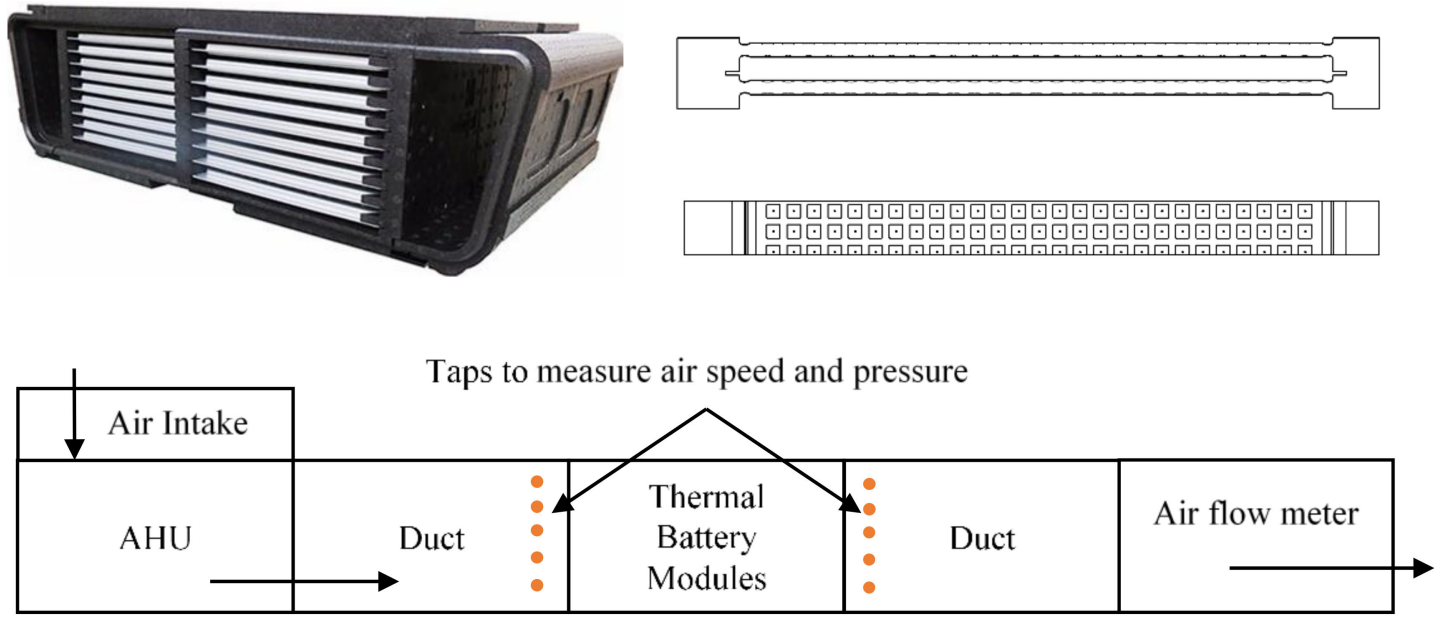

Figure 5. Thermal battery, section and top view of existing panel and diagram of the test rig.

The results of experiments and simulations are presented in Table 4, showing that even if the existing panel is not uniform along its width (due to protrusions of $10 \mathrm{~mm} \times 10 \mathrm{~mm}$ along the panel), 2D simulations present sensible results with increasing pressure drop due to the number of $\mathrm{TB}$ and air flow compared to experimental measurements.

Table 4. Experiment and simulation pressure drop and their difference.

\begin{tabular}{|c|c|c|c|c|c|c|c|c|c|}
\hline \multicolumn{4}{|c|}{ Experiment Pressure Drop (Pa) } & \multicolumn{3}{|c|}{ Pressure Drop Simulation in 2D (Pa) } & \multicolumn{3}{|c|}{$\begin{array}{c}\text { Difference between Experiment } \\
\text { and Simulation (Pa) }\end{array}$} \\
\hline Air flow (Re) & $1 \mathrm{~TB}$ & $2 \mathrm{~TB}$ & $3 \mathrm{~TB}$ & $1 \mathrm{~TB}$ & $2 \mathrm{~TB}$ & $3 \mathrm{~TB}$ & $1 \mathrm{~TB}$ & $2 \mathrm{~TB}$ & $3 \mathrm{~TB}$ \\
\hline 10089 & - & 10.30 & - & - & 11.07 & - & - & 0.77 & - \\
\hline 18736 & 15.38 & 28.58 & 40.98 & 19.80 & 37.77 & 52.69 & 4.42 & 9.19 & 11.71 \\
\hline 21600 & 20.20 & 43.47 & 51.24 & 25.51 & 45.92 & 67.29 & 5.32 & 2.44 & 16.05 \\
\hline
\end{tabular}

\subsubsection{D Simulations}

Based on the five KPIs for selection, 13 surface geometries were generated in 2D (Table 4) as the selected 3D design is uniform along its width. The selected design has longitudinal ridges; these drive the air uniformly along its width and ensure a more uniform melting and solidification process. It also helps to avoid panel leaking due to unbalanced pressure and non-uniform stress due to panel expansion and contraction.

A parametric analysis varying ridge height, ridge pitch and ridge radius evaluated pressure drop and heat transfer. These dimensions are represented in Table 4 . The flow rate in terms of Reynolds number used for all 2D simulations were based on the inlet hydraulic diameter of the channel and ranged from 7200 to 21,600 .

The optimum design selected from 2D simulations was used for refinements. With surface dimensions unchanged, nine new designs evaluated the gap between panels, panel thickness and number of panels. The refined shapes (24 to 32) were based on the number of panels (4-9) and the thickness of the panel [0.069 $\left.<T_{t} / \mathrm{T}<0.151\right]$ in order to increase the volume of PCM per stack. Cost of manufacturing and pressure drop were the KPI's analysed in this simulation.

\subsection{Data Reduction}

\subsubsection{Numerical Design}

The heat transfer between panel and air was calculated by the energy balance through the air crossing the control volume (Figure 3 ) and is given by:

$$
\dot{Q}_{\text {air }}=\dot{m}_{\text {air }} C_{p(\text { air })}\left(T_{o}-T_{i}\right)
$$


where: $\dot{m}_{\text {air }}$ is the air mass flow rate in $\frac{\mathrm{kg}}{\mathrm{s}} ; C_{p(\text { air })}=1007\left[\frac{\mathrm{J}}{\mathrm{KgK}}\right] ; T_{i}=26^{\circ} \mathrm{C} ; T_{0}$ is the air outlet temperature calculated by CFD, $\dot{Q}_{a i r}$ is in Watts and it is assumed that there are no losses through the walls. The Nusselt number is given by:

$$
N u=\frac{h D_{h}}{k_{\text {air }}}
$$

where $D_{h}$ is the hydraulic diameter, $k_{\text {air }}$ is the thermal air conductivity and $h$ is the convective heat transfer coefficient.

To evaluate $h$, a control volume was applied (Figure 3) and all energy released by the air $\left(\dot{Q}_{\text {air }}\right)$ is absorbed through convection $\left(\dot{Q}_{c}\right)$ by the panel (Equation (3)),

$$
\begin{gathered}
\dot{Q}_{a i r}=\dot{Q}_{c} \\
\dot{m}_{a i r} C_{p(a i r)}\left(T_{m, o}-T_{m, i}\right)=h A_{\text {panel }} \Delta T
\end{gathered}
$$

where $A_{\text {panel }}=L_{\text {panel }} \cdot W_{\text {panel }}$. For cases using constant surface temperature, the difference between hot and cold is given by a logarithmic mean temperature difference $\Delta T_{L M D T}$ [25]:

$$
\Delta T_{L M D T}=\frac{\left(\Delta T_{o}-\Delta T_{i}\right)}{\ln \left(\frac{\Delta T_{o}}{\Delta T_{i}}\right)}=\frac{\left(T_{s}-T_{o}\right)-\left(T_{s}-T_{i}\right)}{\ln \left[\left(T_{s}-T_{o}\right) /\left(T_{s}-T_{i}\right)\right]}
$$

where $T_{m, o}$ is the outlet fluid temperature; $T_{m, i}$ is the inlet fluid temperature and $T_{s}$ is the surface temperature. Adding Equation (4) in Equation (3):

$$
h=\frac{\dot{m}_{\text {air }} C_{p(\text { air })}\left(T_{o}-T_{i}\right)}{\left(L_{\text {panel }} \cdot W_{\text {panel }}\right)\left(\frac{\left(T_{s}-T_{o}\right)-\left(T_{s}-T_{i}\right)}{\ln \left[\frac{T_{S}-T_{o}}{T_{s}-T_{i}}\right]}\right)}\left[\frac{W}{m^{2} K}\right]
$$

The introduction of ridges requires more pumping power from the system. The thermal enhancement factor $(\eta)$ [26] analyses the ratio of the convective heat transfer of the augmented surface over a smooth surface at a constant pumping power and is given by:

$$
\eta=\frac{\left(\frac{N u}{N u_{o}}\right)}{\left(\frac{\Delta p}{\Delta p_{o}}\right)^{1 / 3}}
$$

where $N u_{o}$ and $\Delta p_{o}$ are the Nusselt number and the pressure drop in a smooth panel. Values higher than 1 suggest an increase in heat transfer or reduction in pressure drop when compared to a smooth panel, and values lower than 1 suggest the opposite.

\subsubsection{Laboratory Test}

Similarly to the numerical design, the heat transfer in the laboratory test was analyzed in terms of Nusselt number. The temperature surface was averaged and the average convection heat transfer coefficient was calculated by Equation (9):

$$
h=\frac{Q_{c o n v}}{A\left(\widetilde{T}_{s}-T_{b}\right)}
$$

where $A$ is the panel surface area, $T_{i n}$ and $T_{\text {out }}$ is the air inlet and outlet temperature acquired by thermocouples.

$$
T_{b}=\left(T_{o u t}+T_{i n}\right) / 2
$$


and $\widetilde{T}_{\boldsymbol{s}}$ is the surface temperature average of all thermocouples and is given by equation 11 :

$$
\tilde{T}_{s}=\sum_{i=1}^{N} T_{s i} / N
$$

where $N$ is the number of thermocouples and $Q_{c o n v}$ is the heat transfer between panels and air given by:

$$
Q_{\text {air }}=Q_{\text {conv }}=\dot{m}_{\text {air }}\left(c_{\left.p_{\text {air }} \text { out }\right)} T_{\text {out }}-c_{p_{\text {air }} \text { (in) }} T_{\text {in }}\right)
$$

where $\dot{m}_{\text {air }}$ is the air mass flow rate in $\frac{\mathrm{kg}}{\mathrm{s}} ; c_{p_{\text {air }}}$ in $\frac{\mathrm{J}}{\mathrm{kgK}}$.

With the heat of convection evaluated, it is possible to estimate the averaged Nusselt number (Equation (2)) and the Thermal Enhancement Factor (Equation (6)).

To estimate $N u_{o}$ and $\Delta p_{o}$, the Dittus-Boelter (Equation (13)) correlation was used to validate the Nusselt number results, which is:

$$
N u_{D B}=0.023 R e_{D}^{4 / 5} \operatorname{Pr}^{n}
$$

where $n=0.4$ for the fluid being heated and $n=0.3$ when the fluid is being cooled. This procedure was used by Promvonge [16] in a similar experiment.

To evaluate the energy stored and released, Equations (12) and (13) were used to evaluate the PCM-air heat exchanger performance.

$$
\begin{aligned}
& Q_{c}=\int_{0}^{t} \dot{m}_{\text {air }} c_{p, \text { air }}\left(T_{\text {out }}-T_{\text {in }}\right)_{\text {air }} d t \\
& Q_{h}=\int_{0}^{t} \dot{m}_{\text {air }} c_{p, \text { air }}\left(T_{\text {out }}-T_{\text {in }}\right)_{\text {air }} d t
\end{aligned}
$$

\subsection{Laboratory Testing}

To evaluate the fabricated panel, it is important to analyse (a) the effect of inlet temperature on melting and solidification stages; (b) the effect of airflow on charging and discharging; (c) the effects of the distance between panels; (d) the energy exchanged between air and panel during charging and discharging and (e) the charging and discharging time. The design of the new panel surface was not focused on the behaviour of attachment and detachment at the boundary layer. Instead, the overall heat transfer was the variable of interest. Furthermore, the test is intended to confirm and validate the numerical design. As a result, the methodology of previous works found on literature $[14,16,17]$, where thermocouples are attached to the test surface were used.

Thus, three tests evaluated the new design and compared it with the existing and a flat panel. The first test analysed the heat transfer with different panel gaps, the second test investigated the pressure drop and the third test studied the melting and solidifying process. The following summarises the experimental steps.

1. Laboratory test 1: Investigation of heat transfer and pressure drop of one panel with different gaps between panels.

a. A test rig consisting in a variable fan, rectangular ducts and a test section was mounted to evaluate the heat transfer of new and the existing panel, (Figure 2);

b. Each half of panel was filled with a potting compound and a resistance wire;

c. A power supply of $13.5 \mathrm{~W}$ heated each panel and 14 thermocouples measured the surface temperature of the panels every $10 \mathrm{~s}$;

d. One thermocouple before and 3 after the test section measured the increase in air temperature every $10 \mathrm{~s}$;

e. Three different airspeeds were tested $(0.5,1.0$ and $1.5 \mathrm{~m} / \mathrm{s}$ or $\mathrm{Re} \cong 2000,4100$ and 6061, respectively) at three different gaps (8,9 and $10 \mathrm{~mm}$ gap). Each test finished after the steady state was achieved for at least $30 \mathrm{~min}$; 
f. With panel surface and air temperature data acquired, the heat of convection was calculated through energy balance and the Nusselt number was estimated.

g. To validate the results acquired on the rig, a smooth panel with the same gaps and airspeed was simulated with ANSYS Fluent. The Nusselt number estimated in the test was validated by Gnielinski's correlation (Equation (10);

h. Results of pressure drop and heat transfer from the smooth panel were used to estimate the Thermal Enhancement Factor (TEF);

i. The optimum configuration considering heat transfer and efficiency was used in the second experiment.

2. Laboratory test 2 (Figure 6a): Pressure drop along 1, 2 and 3 TB

a. A test rig consisting in a fan and rectangular ducts was mounted to measure the pressure drop of 1, 2 and 3 thermal batteries for existing and new TB.

b. The airflow of the tests varied between $50-150 \mathrm{~L} / \mathrm{s}$ with steps of $20 \mathrm{~L} / \mathrm{s}$;

c. The test was concluded when the pressure drop for new and existing panels was tested for 1, 2 and 3 TB.

3. Laboratory test 3 (Figure 6b): Melting and solidifying process of 1 and 2 TB Ws tested to compare the efficiency between the existing and the new panel. The energy balance from the airside was applied to evaluate the charging and discharging process as well as the time necessary.

a. A test rig consisting in a fan, rectangular ducts and a cooling/heating source with a control system able to provide stable temperature during charging and discharging tests (charging setpoint of $15^{\circ} \mathrm{C}$ and heating setpoint of $30^{\circ} \mathrm{C}$ adjusted on the cooling/heating source (Hybrid Thermal Mixing Low Temperature Hot Water: HTM LTHW [27]));

b. The existing and new panels were filled and sealed with the PCM CrodaTherm ${ }^{\mathrm{TM}}$ 24 [28];

c. One thermocouple before and 2 after the test section measured the air temperature every $15 \mathrm{~s}$; two thermocouples was judged to be enough as the variation between them was small.

d. 12 thermocouples were attached on the panel surface located at the middle of the thermal battery ( 6 on the upper and 6 on the bottom surface) plus 6 thermocouples were attached on the panel located below and above the middle panel;

e. The fixed airflow of $75 \mathrm{~L} / \mathrm{s}$ for all tests was measured using the airflow meter Sensing Precision Balance Master 4250.

The thermocouple calibration used a thermal bath (CTB9500) and a $0.001{ }^{\circ} \mathrm{C}$ resolution Hand Results and analysis held thermometer (CTH7000). Thermocouples type K were joined with the Thermocouple Welder L60+. Five points evenly distributed from 8 to $50{ }^{\circ} \mathrm{C}$ were logged by the DataTaker DT80 with the extension (CEM20) and used to calibrate the thermocouples. More than one hundred thermocouples were used in this study. A regression analysis found an average error of $0.36^{\circ} \mathrm{C}$ with a standard deviation of $\pm 0.52{ }^{\circ} \mathrm{C}$. The airflow meter (Sensing balance master) has an accuracy of $\pm 3 \%$ and the anemometer (Testo $410 \mathrm{i}$ ) $\pm 2 \mathrm{~m} / \mathrm{s}$. Errors were evaluated according to Moffat [29]. The estimated uncertainty of 14 thermocouples is $1.35^{\circ} \mathrm{C}$; heat transfer $3.7 \%$, TEF $8.6 \%$ and Nusselt Number $5.6 \%$. 


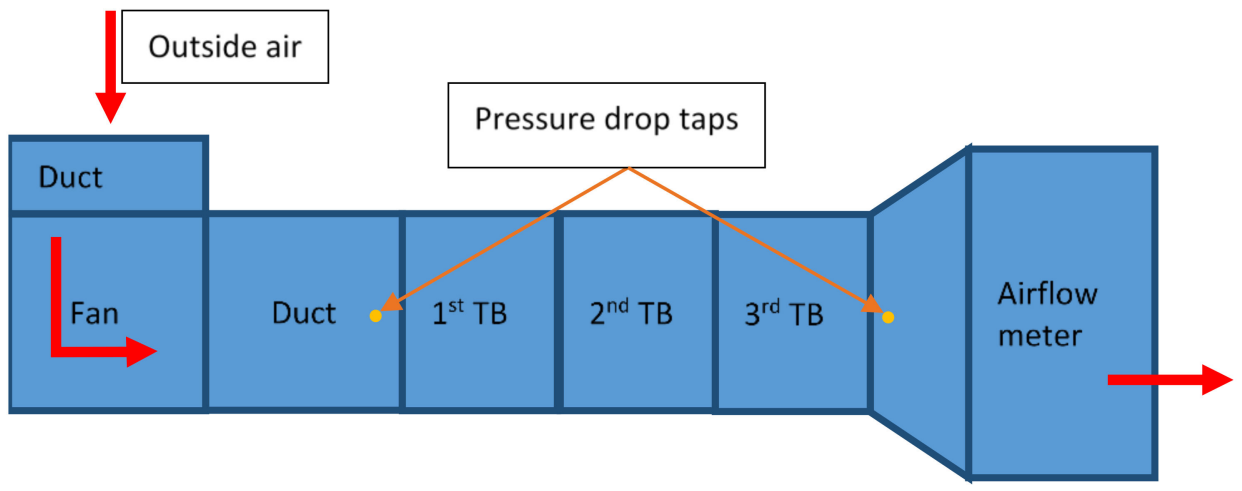

(a)
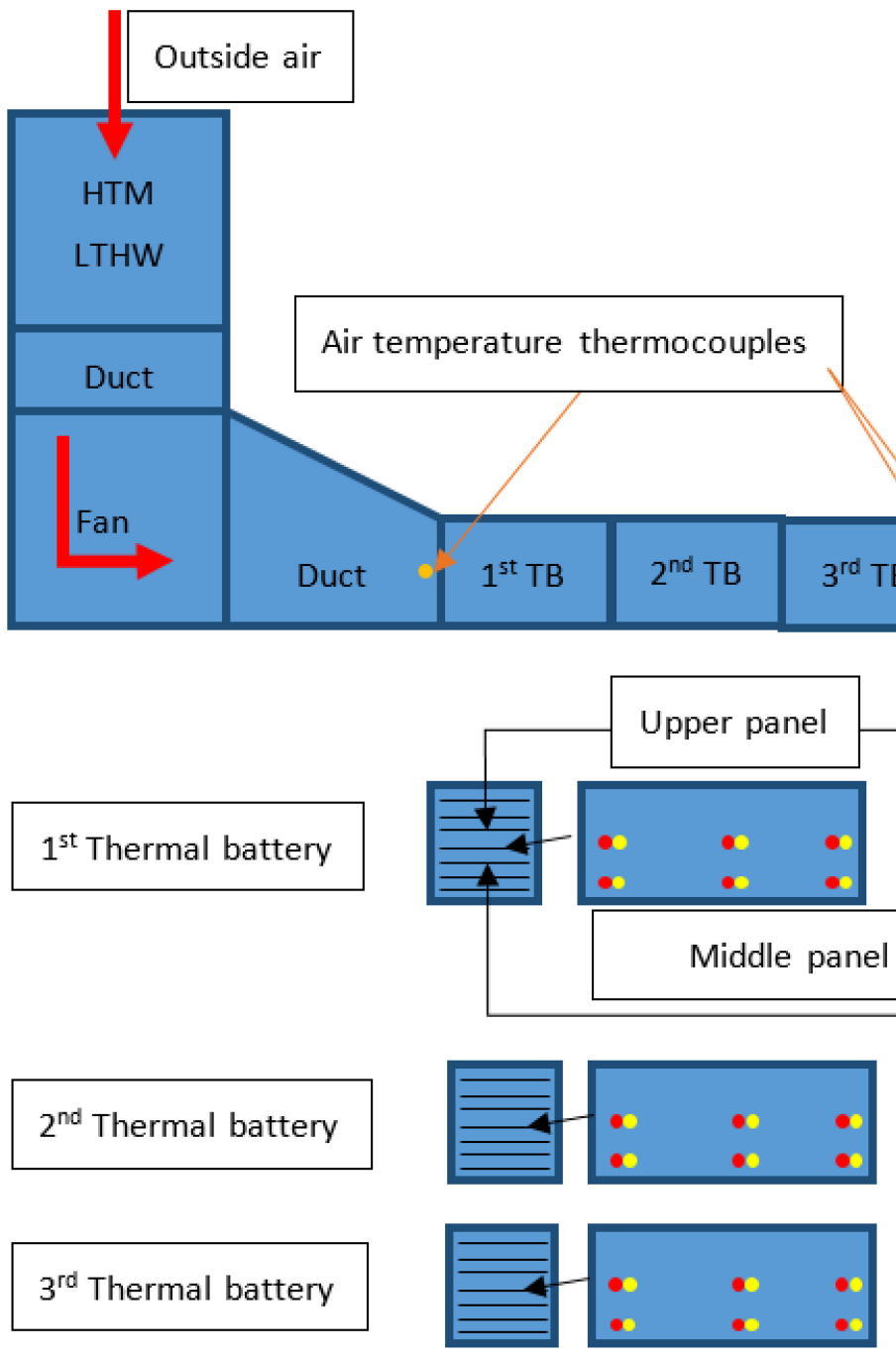

(b)

Figure 6. (a) Diagram of the test rig for pressure drop test. (b) Test configuration of 1, 2 and 3 TB for existing and new panel.

\section{Results and Analysis}

3.1. Numerical Design

3.1.1. 3D Simulations

Nine 3D panels with different configurations at $\operatorname{Re}=18,736$ plus the existing, dimpled and teardrop panel were generated. The results of Nusselt number, pressure drop and the ratio between the existing and smooth panels are presented in Figure 7. 


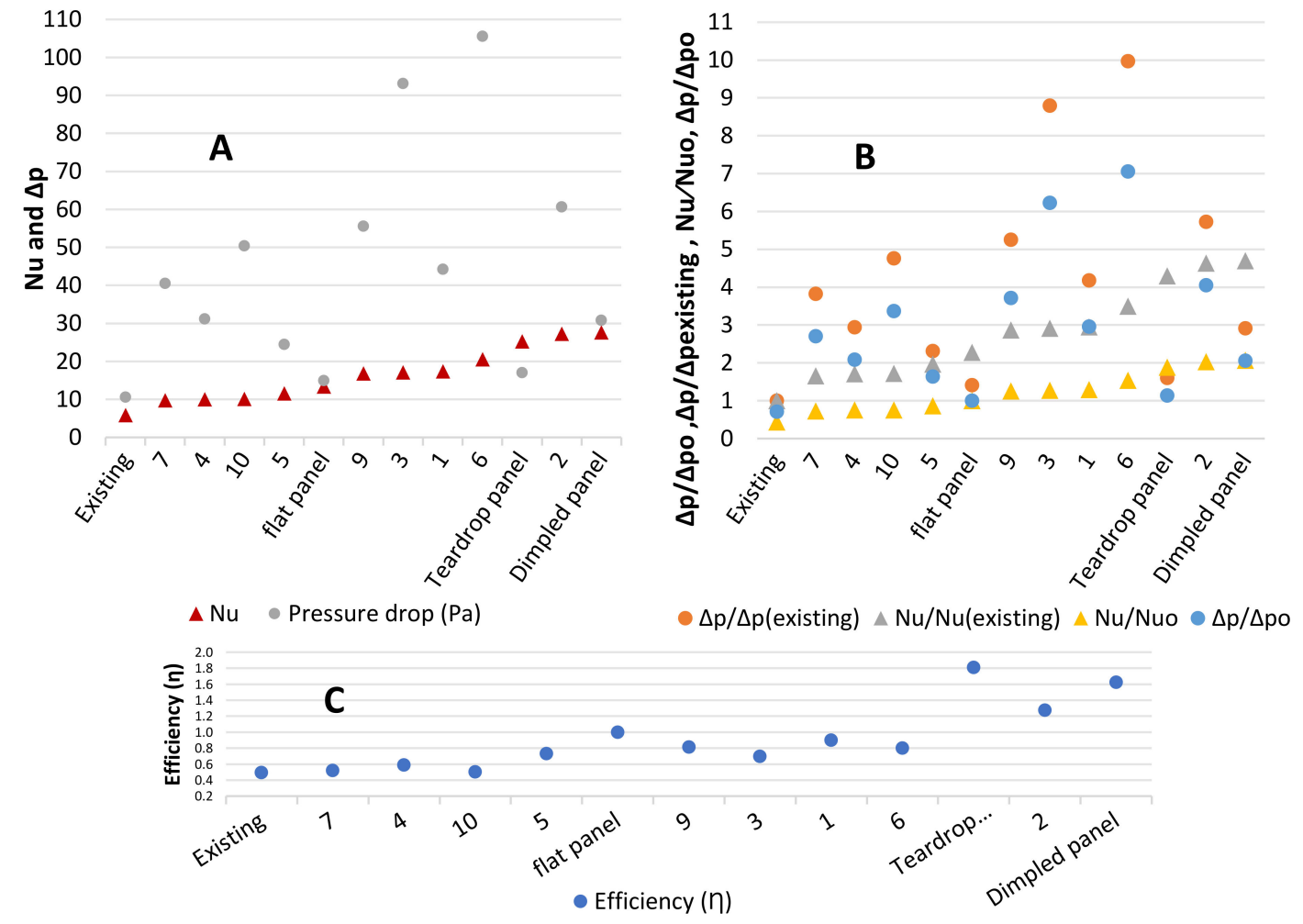

Figure 7. Nusselt number and pressure drop ratio for existing and smooth panel (A) and Nusselt number and pressure drop $(\mathbf{B})$ at $\operatorname{Re}=18,736$ for $3 \mathrm{D}$ simulations $(\mathbf{C})$.

Figure 7 (up left) shows that all panels present a Nusselt number higher than the existing panel with the dimpled panel being the highest for a smaller increase in the pressure drop. Shape 6 presents a higher pressure drop (10 times higher than the existing panel) which makes it unfeasible; for the same reason, shape 3 was discarded. Shapes 1 and 2 also have a good heat transfer but the lozenges along its width doubles the cost of production and makes it unfeasible; for the same reason, the dimpled and the teardrop panel was discarded. Shape 9 is the panel with simplest design (ridges along its width through the whole panel) and capable of increasing the Nusselt number three times, with a pressure drop five times higher compared to the existing panel (Figure 8). These ratios can be seen in Figure 7 (right) where Nusselt number and pressure drop with existing and smooth panel are presented. Figure 7 (bottom) shows that shape 2, teardrop and dimpled panel, has an efficiency higher than 1 , which means that the gains in heat transfer are higher than the gains in pressure drop, while shapes 6, 1,9 and 3 increased the pressure drop more than the heat transfer.

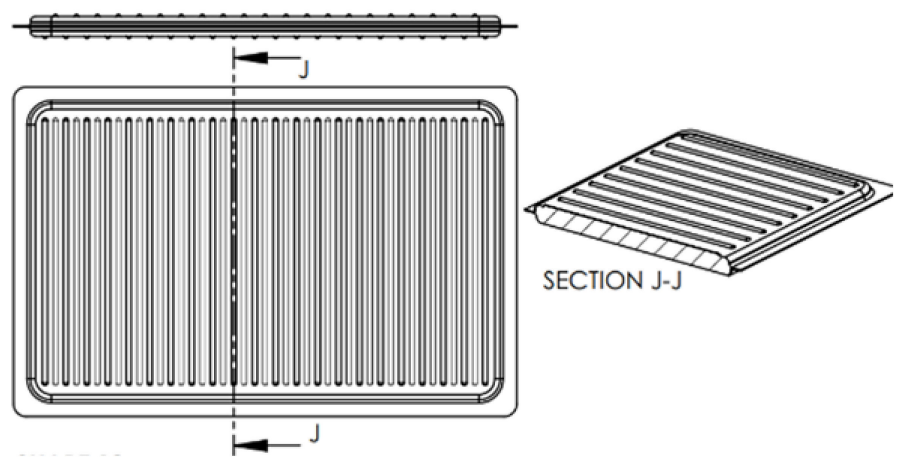

Figure 8. Views of Shape 9. 
Based on these results and due to the simplicity of its design and manufacturing cost, shape 9 (Figure 8) was chosen for additional refinements. Moreover, a panel uniform along its width gives rigidity to the panel.

\subsubsection{D Simulations}

The design of Shape 9 allows the simulations to be conducted in 2D as it is uniform along its width. Thirteen variations (Table 4 , Shapes 11 to 23) were generated and stacked in 7sevenpanels per module to perform a parametric analysis of the spacing between ridges, ridge height and radius for Reynolds number varying from 7200 to 21,600. Figure 9 shows the temperature distribution of Shape 11, where the outlet temperature and inlet pressure were averaged and used to calculate the Nusselt number and pressure drop.

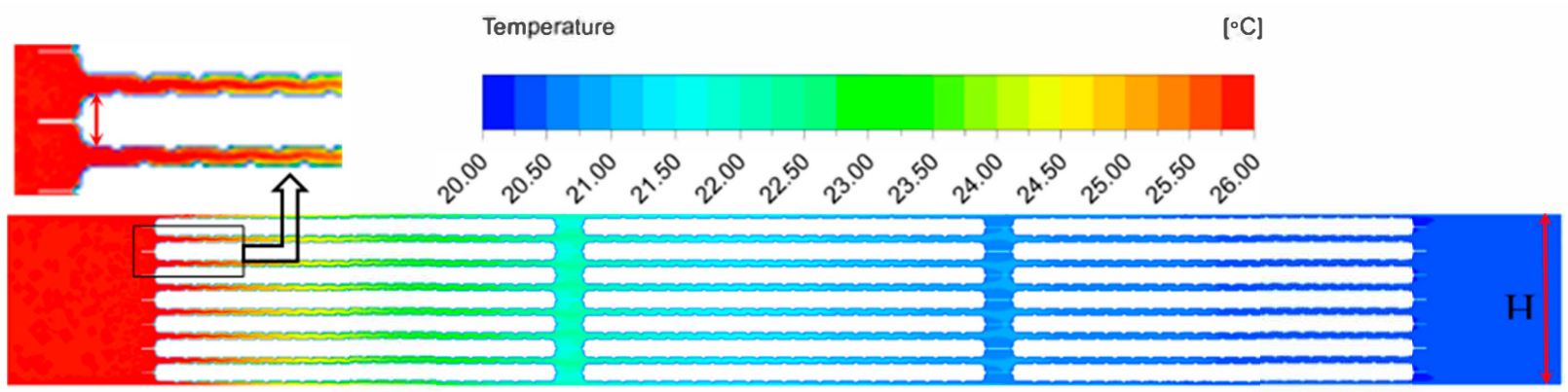

Figure 9. Temperature distribution of Shape 11 at $\operatorname{Re}=18,736$.

Figure 10 shows that shape 11 has, at most Reynolds numbers, the highest heat transfer, representing $75 \%$ more heat transfer on average when compared to a smooth panel. The efficiency of this shape is close to 1.0 on average, which reflects that the heat transfer and pressure drop increased in a similar rate while other shapes have a higher increase in pressure.
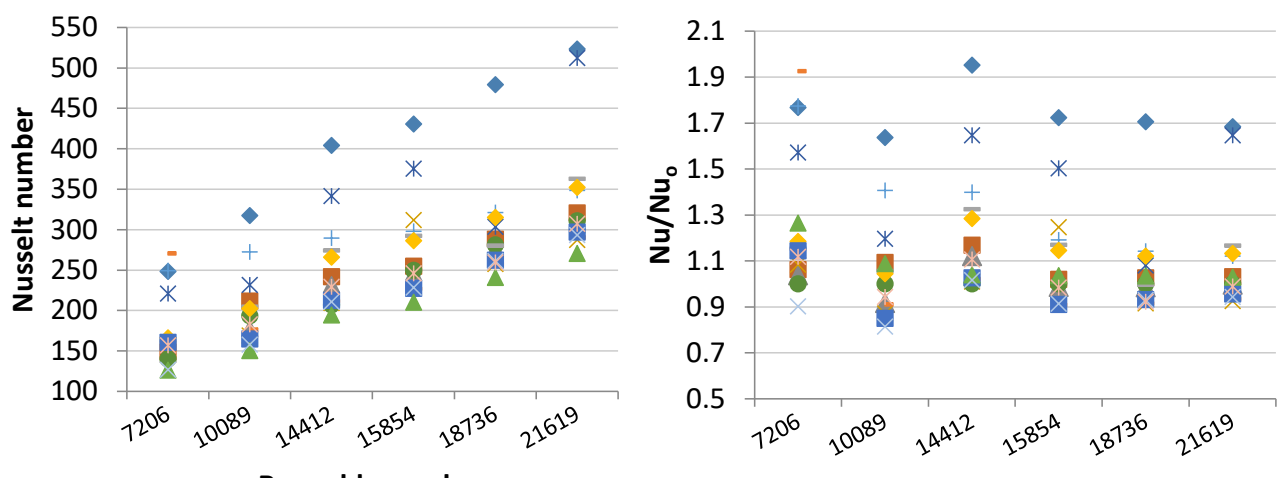

Reynolds number

\section{Reynolds number}

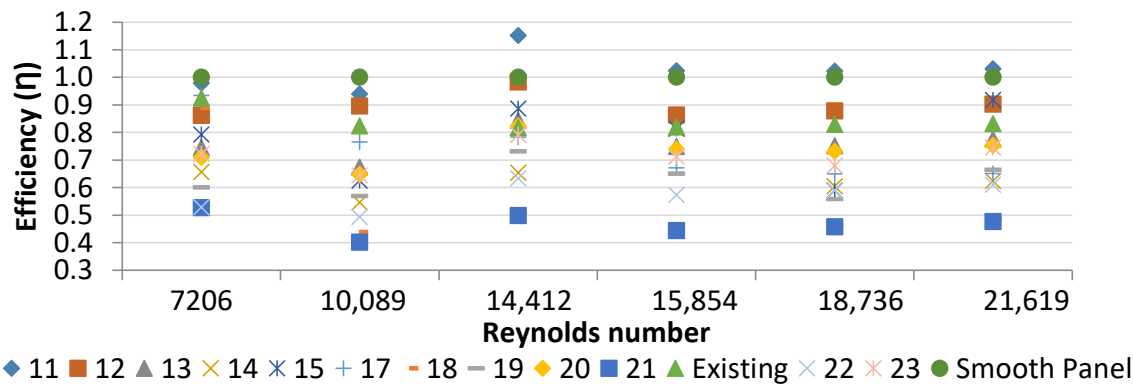

Figure 10. Nusselt number and Nusselt number ratio from a smooth panel. 
As Shape 11 was the most effective in terms of heat transfer and pressure drop, the same gap distance and surface geometry was used to generate nine additional cases (Table 4 , shapes 24 to 32 ) by varying panel thickness, spacing between panels and total panels per module of TB.

As a result, shape 29 had the worst performance when compared to other shapes. Conversely, shapes 26, 11 and 24 (Figure 11, upper left) have the highest Nusselt numbers at any Reynolds number. This increase allows a fast response by the PCM-Air heat exchanger when the heat load increases suddenly.
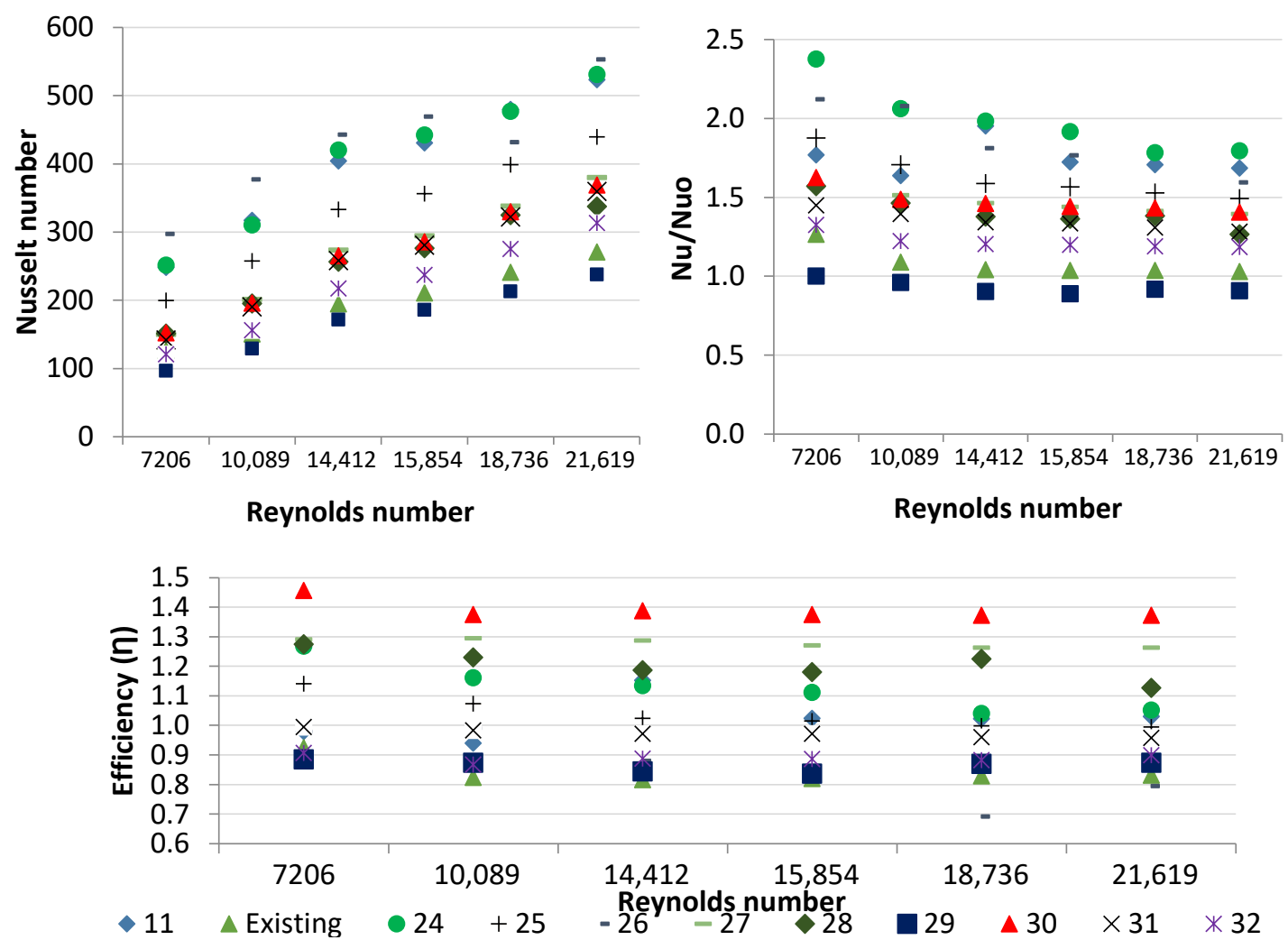

Figure 11. Nusselt number and smooth panel ratio and Nusselt number for refined panels.

When the Nusselt number is compared to a smooth surface $\left(N u / N u_{0}\right)$, shapes 24,26 and 11 present the best results, showing an average increase of 2, 1.8 and 1.75 as shown in Figure 11 (right) where the ratio is shown for all cases. The inclusion of ridges favored heat transfer by the increase of turbulence at lower Reynolds number, allowing a reduction in PCM-Air heat exchanger airflow, saving energy and reducing noise. The result also shows that the existing panel performs better than a smooth surface only at low Reynolds numbers (1.27 for 7200). For Reynolds numbers above 10,089 the existing panel have a performance similar to a smooth panel with a $N u / N u_{o}$ lower or equal to 1 .

Figure 11 (bottom) shows that the efficiency of shapes 11, 24, 25, 27, 28 and 30 have values above 1 , which means that the inclusion of ridges enhanced the heat transfer at a lower cost in terms of pressure drop when compared to a smooth surface. Shape 26 has the best performance in terms of Nusselt number but the higher pressure drop lowers its efficiency ( 0.86 on average). Values below 1 mean that the pressure drop increases in a proportion higher than the Nusselt number, leading to an increase of noise and energy cost with a small benefit on heat transfer.

When the volume of PCM held in a panel is (Table 5) it can be seen that shape 26 holds $20.51 \%$ more PCM when compared to the existing panel while shapes 11 and 24 are able to hold 13.68 and $0.08 \%$ more, respectively. 
Table 5. Volume change in comparison with existing panel.

\begin{tabular}{ccccccccccc}
\hline & $\mathbf{1 1}$ & $\mathbf{2 4}$ & $\mathbf{2 5}$ & $\mathbf{2 6}$ & $\mathbf{2 7}$ & $\mathbf{2 8}$ & $\mathbf{2 9}$ & $\mathbf{3 0}$ & $\mathbf{3 1}$ & $\mathbf{3 2}$ \\
\hline & $13.68 \%$ & $0.08 \%$ & $2.63 \%$ & $20.51 \%$ & $-2.56 \%$ & $-2.56 \%$ & $-2.56 \%$ & $-2.56 \%$ & $3.93 \%$ & $2.31 \%$ \\
Panels/module & 7 & 9 & 8 & 6 & 6 & 6 & 5 & 4 & 8 & 9 \\
\hline
\end{tabular}

To ensure that a small fan can provide the required airflow for the selected shapes, the pressure drop of the panels against the fan head curve was plotted. As it can be seen in Figure 12, the air handling unit can provide sufficient pressure at the required airflow to overcome this drop for shapes 11, 24 and 25.

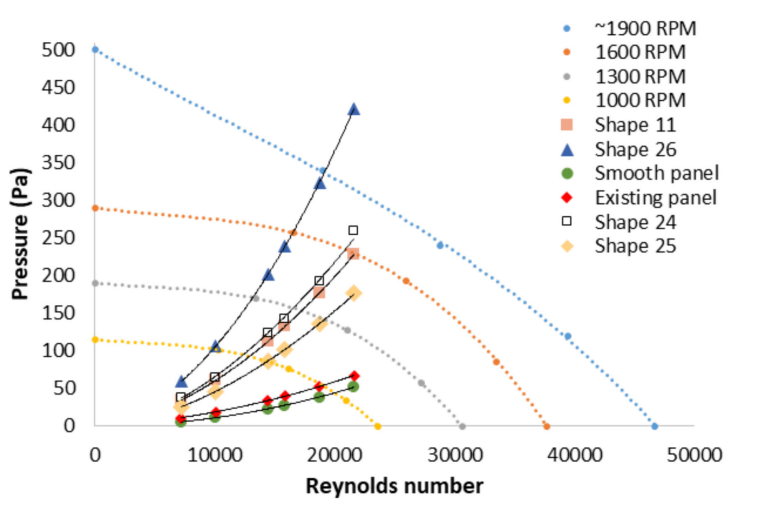

Figure 12. Head curve of panels 11, 24, 25 and 26 as well as the smooth and the existing panel with fan curves at different rotation speeds.

Based on these results, shape 11 was selected to be fabricated.

\subsection{Laboratory Test}

With the panel selected and fabricated (Figure 13), a laboratory test was performed in order to evaluate the new panel in comparison with the existing panel and a flat panel.

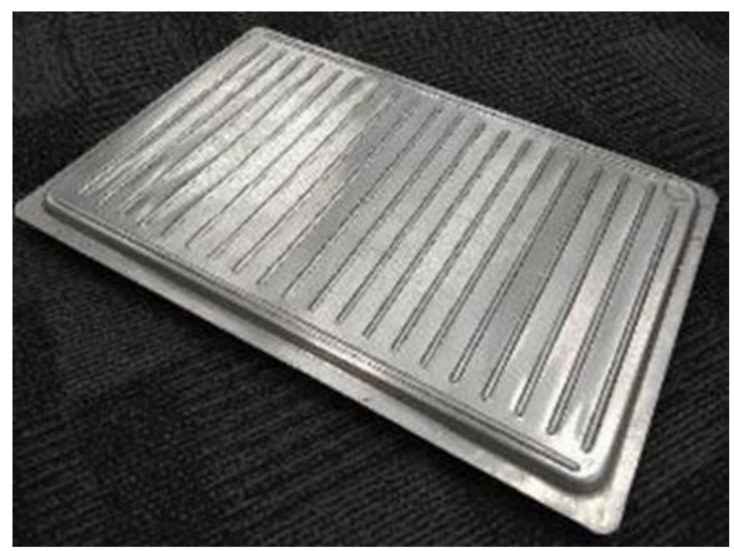

Figure 13. Fabricated panel.

3.2.1. Heat Transfer and Pressure Drop of One Panel with Different Gaps between Panels

At low Reynold numbers, the new panel performed better than the existing panel only at $8 \mathrm{~mm}$ gap (Table 6). Conversely, at higher Reynolds numbers $(\operatorname{Re}=4067$ and 6061), the new panel increased the heat transfer at significant values for 8 and $9 \mathrm{~mm}$ gaps. 
Table 6. Nusselt number improvement from existing to new panel.

\begin{tabular}{cccc}
\hline Reynolds Number & $\mathbf{8}$ mm Gap & $\mathbf{9}$ mm Gap & $\mathbf{1 0 ~} \mathbf{~ m m ~ G a p ~}$ \\
\hline 1954 & $20 \%$ & $-5 \%$ & $-26 \%$ \\
4067 & $94 \%$ & $36 \%$ & $5 \%$ \\
6061 & $124 \%$ & $72 \%$ & $77 \%$ \\
\hline
\end{tabular}

For $\operatorname{Re}=6061$ (airflow used during PCM-Air heat exchanger charging period), an $8 \mathrm{~mm}$ gap increased the heat transfer by $124 \%$. This is important to note as the charging period occurs during a short period of time and the heat transfer needs to be as efficient as possible. When Nusselt number between the new and the existing panel is compared, $8 \mathrm{~mm}$ gap was shown to be the most effective.

When the gaps between the new panel are compared, a $10 \mathrm{~mm}$ gap is the most effective at $\operatorname{Re}=6061$. The values can be seen in Figure 14 and the percentages in Table 7. Higher rates of heat transfer are important to ensure fast charge and response. The gap of $10 \mathrm{~mm}$ will also lead to a smaller pressure drop and noise. However, fewer panels can be fitted in the thermal battery as its dimensions are limited. At low Reynolds number, the opposite occurs: an $8 \mathrm{~mm}$ gap is the most effective. This is probably due to the attachments and detachments at the boundary layer, which is easier for small gaps and higher Reynolds number.

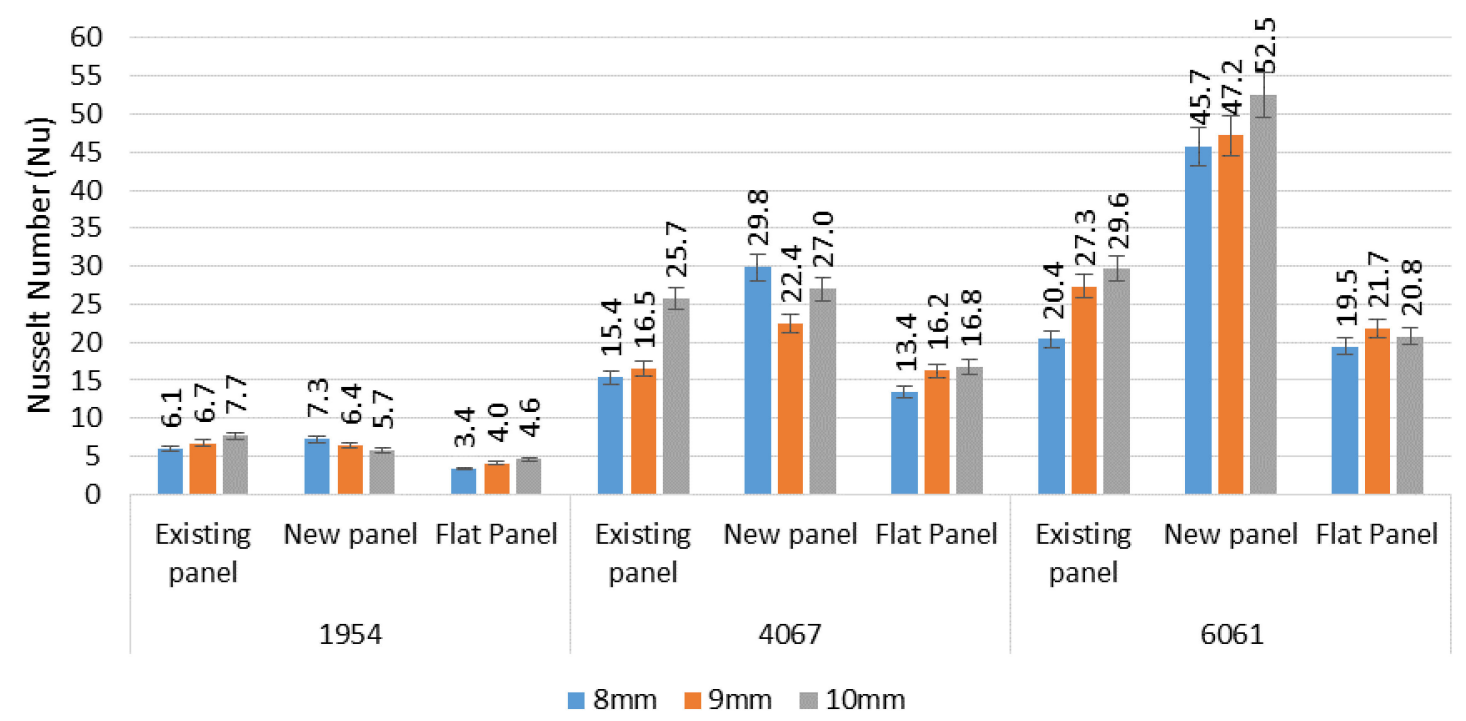

Figure 14. Nusselt number for existing, new and flat panels with error bar showing the uncertainty of 5.6\%.

Table 7. Nusselt number increase between gaps of the new panel (NP: new panel).

\begin{tabular}{cccc}
\hline Reynolds Number & NP 10 mm & NP 10 mm & NP 9 mm \\
\hline 1954 & $-22 \%$ & $-11 \%$ & $-12 \%$ \\
4067 & $-9 \%$ & $21 \%$ & $-25 \%$ \\
6061 & $15 \%$ & $11 \%$ & $3 \%$ \\
\hline
\end{tabular}

Figure 14 also shows the Nusselt number for the flat panel. At $\operatorname{Re}=4067$ and 6061 for 9 and $10 \mathrm{~mm}$ gaps, the existing panel performs similar to the flat panel and shows inefficiency in terms of heat transfer. This increases the charging period, reduces chances to fully charge the thermal battery and requires a lower outdoor temperature during the charging period when compared to the new panel. This information can also be found in Figure 15 where the Nusselt number ratio $\left(N u / N u_{0}\right)$ is presented. Figure 15 shows that the performance is similar at any gap when $\operatorname{Re}=6061$ and the ratio remains the same for 8 and $9 \mathrm{~mm}$. At $\mathrm{Re}=1954$, gaps of 9 and $10 \mathrm{~mm}$ perform worse than the existing panel. 


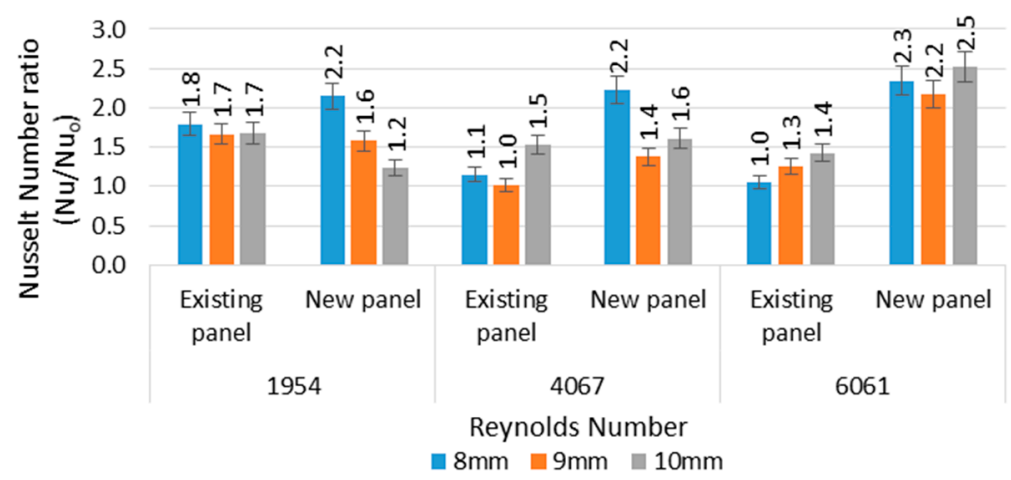

Figure 15. Nusselt number ratio between existing and new panel with flat panel with error bar showing the uncertainty of $7.9 \%$.

\subsubsection{Thermal Enhancement Factor (TEF)}

The pressure drop increase presented in the previous section was expected due to the introduction of ridges. However, to evaluate if the pressure drop increases effectively, or in other words, if the pressure drop increased in a lower rate than the heat transfer, both existing and new panel were compared with the flat panel using Equation (8). These results are presented in Figure 16; showing that the new panel with $8 \mathrm{~mm}$ gap presented the best performance with a TEF higher above 1.8 for the three Reynolds numbers tested with an average of 1.89 .

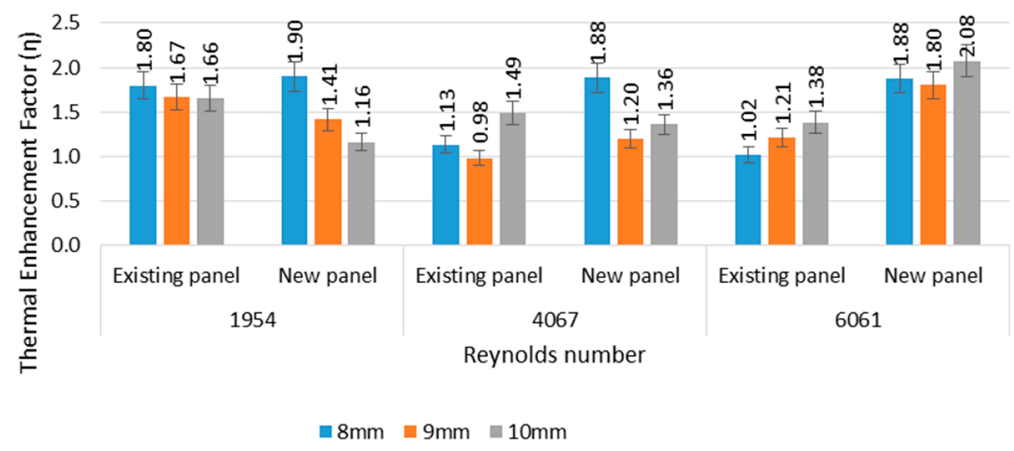

Figure 16. Thermal Enhancement Factor of the existing and new panel with error bar showing the uncertainty of $8.6 \%$.

At low Reynolds number, $(\operatorname{Re}=1954)$ the existing panel performed better than at higher airflows ( $R e=4067$ and 6061). However, the higher TEF is not higher than the new panel with $8 \mathrm{~mm}$ gap. The effectiveness of the new panel is shown more clearly according to the increase of the Reynolds number while the existing panel reduces to an average of 1.20 .

It is interesting to notice that the existing panel has a lower TEF (1.08 on average) when $\mathrm{Re}=4067$ and 6061 at 8 and $9 \mathrm{~mm}$ gaps. This result indicates the inefficiency of the existing panel at higher airflows where the introduction of bulges in the flat panel results in an increase of heat transfer at the same cost of an increase in pressure drop.

Conversely, the highest TEF was found at $\operatorname{Re}=6061$ with $10 \mathrm{~mm}$ gap and represented an increase of $49.9 \%$ when compared to the existing panel (Table 8 ). Table 8 also shows that the highest increase in percentile when compared to the existing panel occurred at $8 \mathrm{~mm}$ gap and $\operatorname{Re}=6061$ and represented an increase of $84.4 \%$. Furthermore, Table 8 also shows that improvements at any Reynolds number was found with a gap of $8 \mathrm{~mm}$. 
Table 8. Percentile increase in TEF from the existing to the new panel.

\begin{tabular}{cccc}
\hline Averaged Reynolds Number & $\mathbf{8} \mathbf{~ m m}$ & $\mathbf{9} \mathbf{~ m m}$ & $\mathbf{1 0 ~} \mathbf{~ m}$ \\
\hline 1954 & $5.9 \%$ & $-15.1 \%$ & $-29.8 \%$ \\
4067 & $66.7 \%$ & $22.0 \%$ & $-8.9 \%$ \\
6061 & $84.4 \%$ & $48.9 \%$ & $49.9 \%$ \\
\hline
\end{tabular}

As a result, after heat transfer, pressure drop and TEF analysis, the new panel with a gap of $8 \mathrm{~mm}$ presented the best choice as it has the highest TEF on average (1.88) and the highest increase in heat transfer $(20 \%, 94 \%$ and $124 \%$, respectively, for $\operatorname{Re}=1954$, 4067 and 6061). The increase in pressure drop was expected due to ridges inclusions and corresponded to $44.7 \%, 65.7 \%$, and 95.1\%, respectively, for $\operatorname{Re}=1954,4067$ and 6061 .

As the pressure drop is an important consideration the capability of the existing fan to provide the necessary airflow when the new panels are stacked in one, two or three TB was investigated. The results are presented in Figure 17.

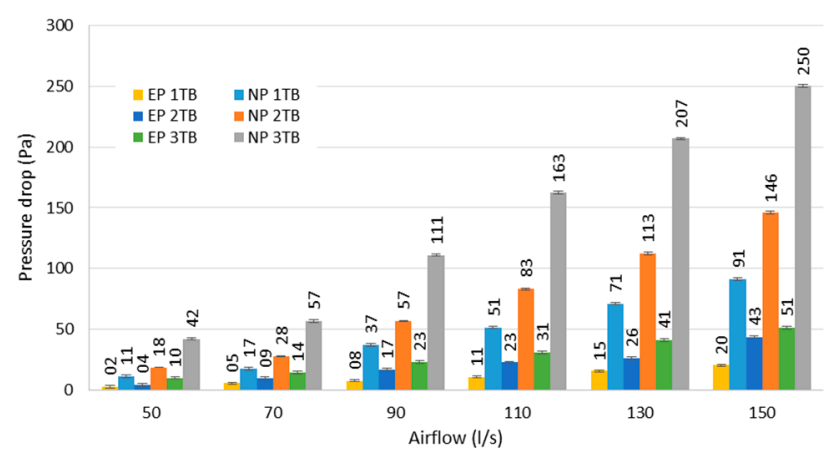

Figure 17. Thermal battery pressure drop test for existing panel (EP) and new panel (NP) with error bar showing the uncertainty of $\pm 1 \mathrm{~Pa}$.

The results show a considerable increase in pressure drop. Table 9 shows an average increase of $345 \%, 258 \%$ and $380 \%$ when the pressure drop of the new and existing thermal batteries are compared. However, the higher heat transfer of the new panel will reduce the fan operation time at higher airflows.

Table 9. Pressure drop increase between existing and new thermal batteries.

\begin{tabular}{cccc}
\hline \multicolumn{3}{c}{ Pressure Drop Increase } \\
\hline Airflow & $1 \mathrm{~TB}$ & $2 \mathrm{~TB}$ & $3 \mathrm{~TB}$ \\
50 & $230 \%$ & $200 \%$ & $300 \%$ \\
70 & $390 \%$ & $240 \%$ & $380 \%$ \\
90 & $390 \%$ & $270 \%$ & $430 \%$ \\
110 & $360 \%$ & $330 \%$ & $410 \%$ \\
130 & $350 \%$ & $240 \%$ & $390 \%$ \\
150 & $350 \%$ & $270 \%$ & $370 \%$ \\
Average & $345 \%$ & $258 \%$ & $380 \%$ \\
\hline
\end{tabular}

The results can also be seen in Figure 18 where the head curve of the fan is plotted with the results obtained from the laboratory tests and the simulations of shapes 11,24 and 26. Figure 18 shows that the fan is capable to provide the airflow required when one, two or three TB are used. 


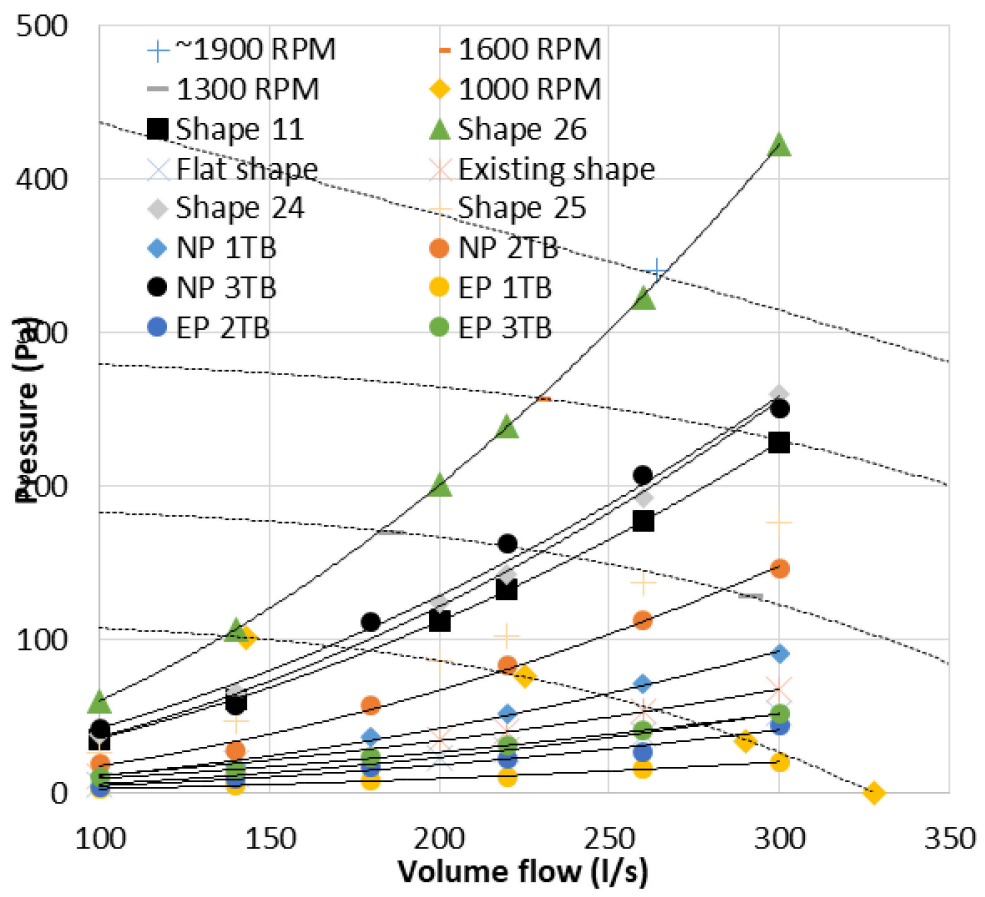

Figure 18. Head curve of the panels simulated and tested.

The results of the design process were compared with the laboratory tests; reasonable agreement is found, considering that assumptions were made during the design process and possible errors obtained during the experiment such as air leakage, reading errors and even the differences between the actual model and the one designed during the manufacturing process. Table 10 shows an average difference of $14 \mathrm{~Pa}( \pm 14.15 \mathrm{~Pa})$ pressure drop between the laboratory tests and the design process. In percentage, this represents an average of $10.5 \%( \pm 11.4 \%)$ which is a good result according to Zhang et al. [30].

Table 10. Pressure drop increase between existing and new batteries.

\begin{tabular}{ccccc}
\hline Airflow (L/s) & Shape 11 & NP 3TB & \% (Experiment/Design) & Difference (Pa) \\
\hline 100 & 34.31 & 41.9 & $22.1 \%$ & 7.6 \\
\hline 140 & 61.28 & 56.7 & $-7.5 \%$ & -4.6 \\
\hline 180 & 112.27 & 111.0 & $-1.1 \%$ & -1.3 \\
\hline 220 & 132.60 & 162.5 & $22.6 \%$ & 29.9 \\
\hline 260 & 176.80 & 207.0 & $17.1 \%$ & 30.2 \\
\hline 300 & 228.24 & 250.4 & $9.7 \%$ & 22.2 \\
\hline \multicolumn{5}{c}{ Standard Deviation $(\sigma)$} \\
\hline
\end{tabular}

\subsubsection{Charging and Discharging Time}

Figure 19 presents the results for one and two TBs; more time is needed to charge and discharge the new TB. This is due to the capability of the new TB to hold $17.5 \mathrm{~kg}$ (total latent heat of $3202.5 \mathrm{~kJ}$ ) against $13.5 \mathrm{~kg}$ (total latent heat of $2470.5 \mathrm{~kJ}$ ) of the existing TB. This $30 \%$ extra PCM made the surface temperature of the new TB solidify and melt gradually while the phase change in the existing TB (which has a thinner panel) is more pronounced. Due to that, Figure 19 clearly shows the onset and endset for both melting and solidifying (20-18 ${ }^{\circ} \mathrm{C}$ and $24-26^{\circ} \mathrm{C}$, respectively) for the existing TB. When two thermal batteries are used a similar behavior is observed. 

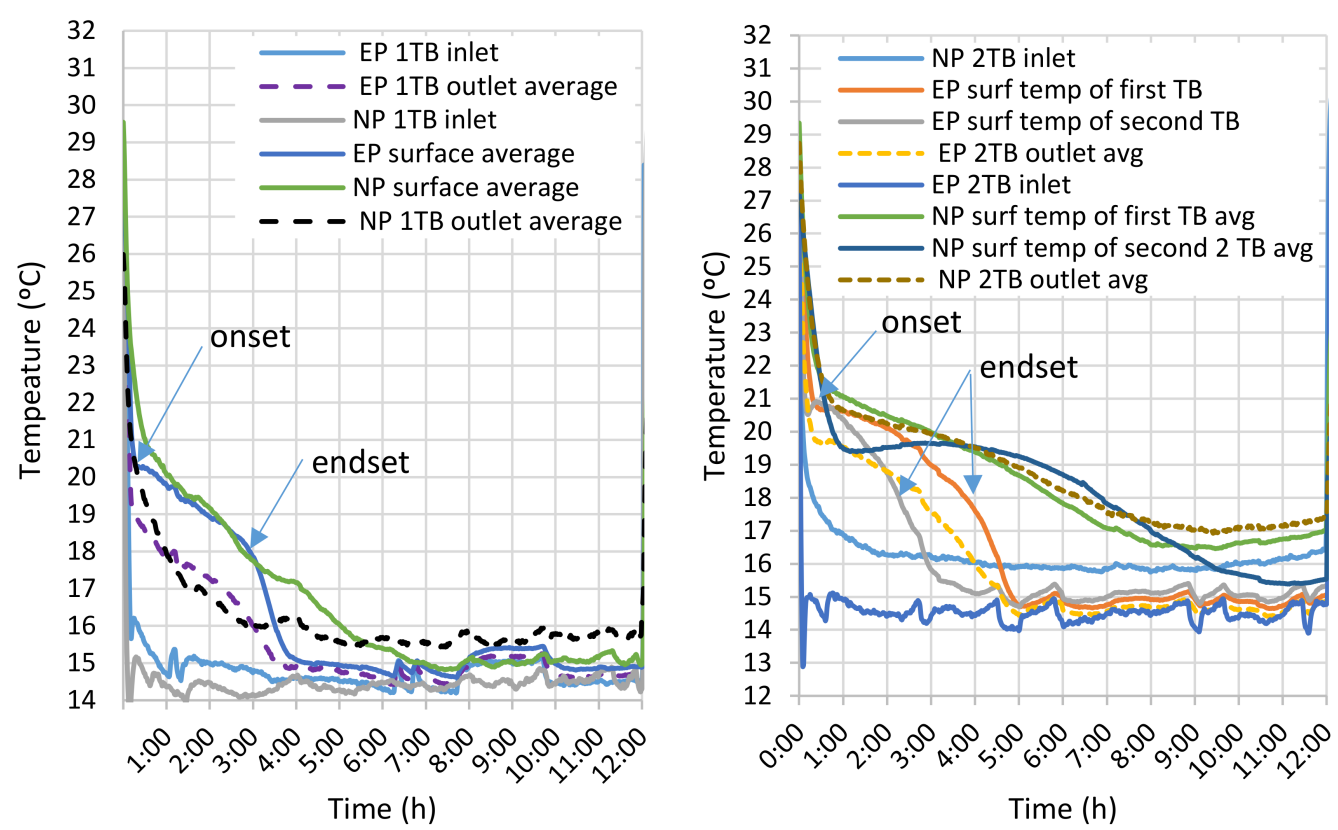

Figure 19. Solidifying temperature for the existing and new panel with one and two thermal batteries.

In terms of time required to melt and solidify, the TB is considered fully charged or discharged when the surface temperature achieves stable conditions. Figure 20 shows that the new TB needs more time to complete the cycle and this is explained by the capacity that the new TB can hold. However, the time required to solidify is lower than the time to melt the PCM properties. This is an interesting result as the mechanical ventilation system needs less time to charge the TB. For one TB, $4 \mathrm{~h}$ is necessary to solidify the existing TB while $5 \mathrm{~h} 30 \mathrm{~min}$ is needed for the new TB, an increase of $38 \%$. For two TB, $8 \mathrm{~h} 30 \mathrm{~min}$ is needed to charge the new TB and while $5 \mathrm{~h}$ is needed for the existing TB, representing $66 \%$ more time.
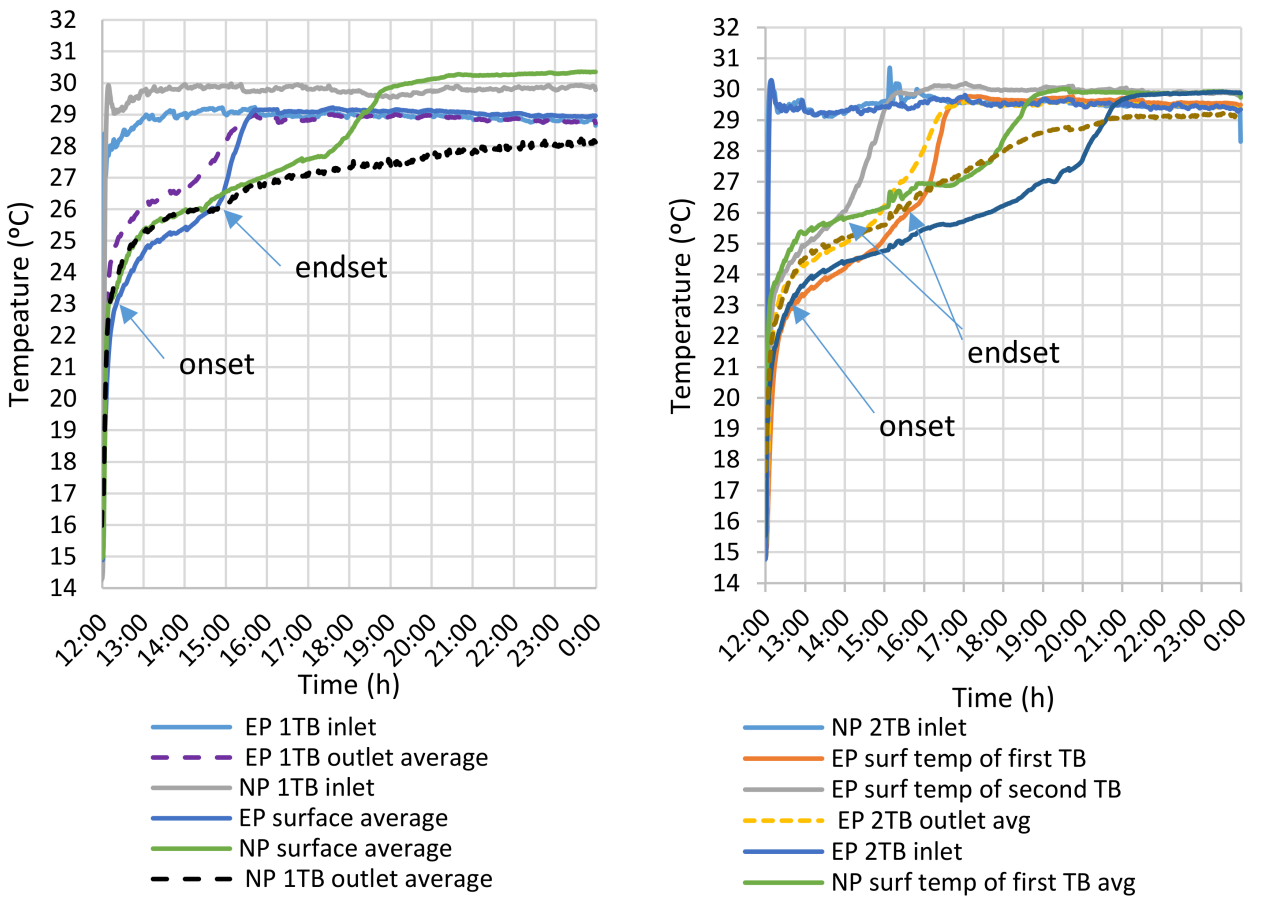

Figure 20. Melting temperature for existing and new panel with one and two thermal batteries. 
When the discharging period is analyzed, the new TB is capable to provide cooling for a longer period of time. This is explained by the additional PCM it can hold. As it can be seen in Figure 20, the outlet temperature gradually increases to reach the inlet temperature. For $1 \mathrm{~TB}$ with the existing panel, the TB is completely discharged after $3 \mathrm{~h} 30 \mathrm{~min}$ while the new TB need approximately $6 \mathrm{~h} 30 \mathrm{~min}$ to completely discharge, an increase of $86 \%$. When a mechanical ventilation system with 2 TB is analyzed, the existing TB is fully discharged after $4 \mathrm{~h} 30 \mathrm{~min}$ while the new TB lasts double the time.

The first laboratory test proved that the new panel is more efficient in terms of heat transfer than the existing panel, an important feature when a faster thermal response is needed. However, Figure 20 (left) shows that the temperature for the existing and new TB increase at the same rate until the PCM starts to melt. This could be explained by the number of panels the existing TB have. With two panels more when compared to the new $\mathrm{TB}$, it has $28 \%$ more surface area and reflects in an outlet temperature similar to the new TB. For the same reason, the outlet temperature during the solidifying period in Figure 20 (right) shows a similar pattern.

\subsubsection{Thermal Load}

During the melting and solidifying process, the air was cooled down or heated up to a correspondent cooling $\left(Q_{c}\right)$ or heating load $\left(Q_{h}\right)$. To estimate those values, Equations (14) and (15) were used. The heating and cooling cycles ceased when the outlet temperature stabilizes and achieve values close to the inlet temperature. These results are presented in Figure 21. Interestingly, even the existing TB having 18 panels per TB and the new TB 14 panels (representing less $22 \%$ heat transfer surface area) the average heating/cooling power are remarkably similar. This result shows that the new panel provides a faster response when compared to the existing panel. Curiously, for the melting period with two $\mathrm{TB}$, the opposite occurs. This is probably caused by fluctuations in temperature during the transition from charge to discharge mode and vice-versa.
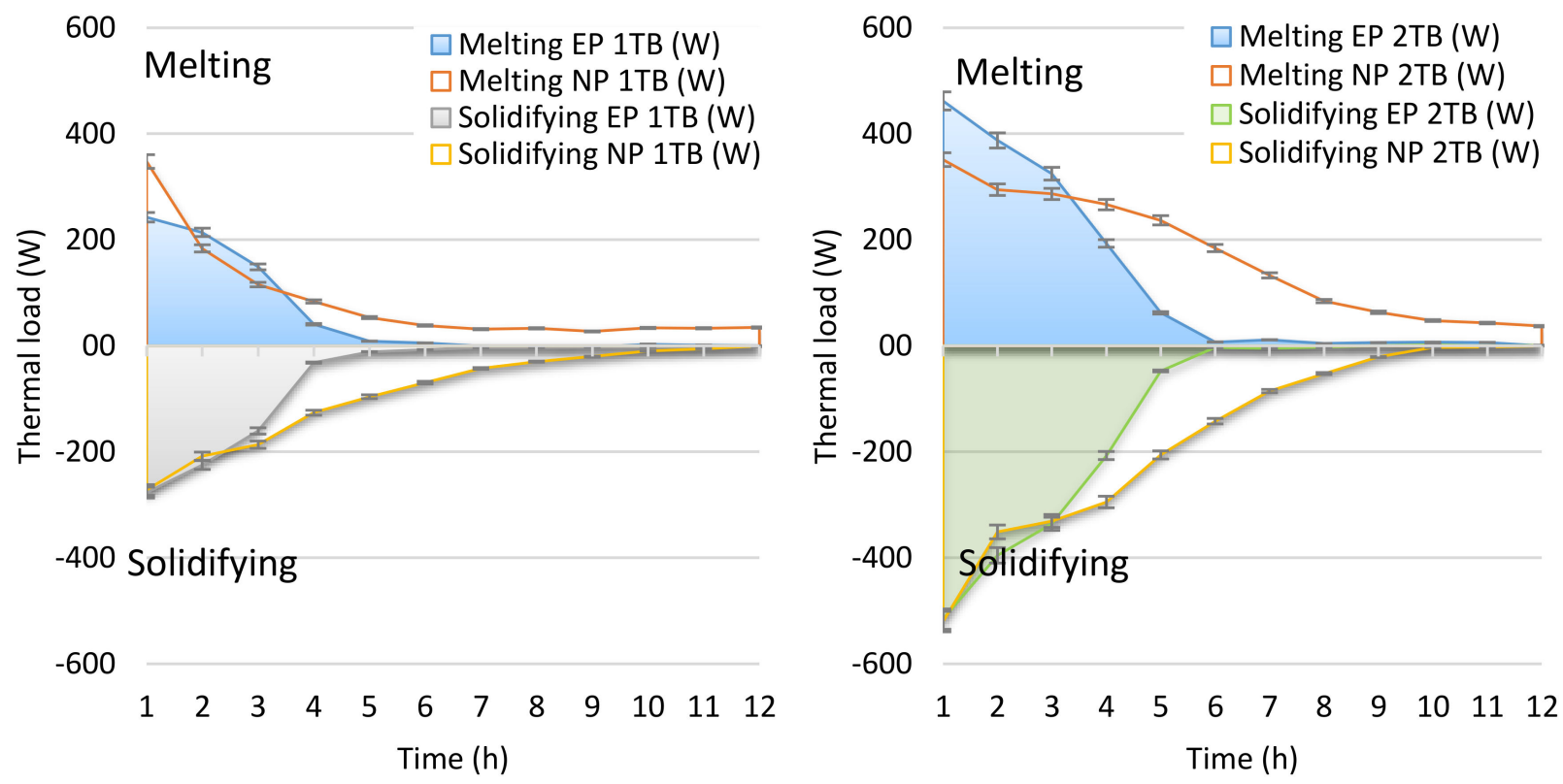

Figure 21. Thermal load for existing and new panel with one (left) and two (right) thermal batteries with error bar showing the uncertainty of $3.7 \%$.

Figure 21 shows that after $4 \mathrm{~h}$ for $1 \mathrm{~TB}$, the TB is fully melted or solidified as a small amount of energy is released or absorbed by the TB. For the new TB, $6 \mathrm{~h} 30 \mathrm{~min}$ is needed to complete the cycle and after this time, the energy released or absorbed by the TB remains stable. A similar pattern occurs with 2 TB (Figure 21, right) where more time for 
solidification was needed. This is explained by $8 \mathrm{~kg}$ of extra PCM the two TB are holding, however, the extra PCM reflects in more energy stored.

The PCM used for this present study (CrodaTherm $24^{\mathrm{TM}}$ ) was subjected to a $3 \mathrm{LC}$ (three-layer-calorimeter) test in order to assess heat storage properties [28]. The results of this test shows that the energy stored during the heat up from 15 to $30^{\circ} \mathrm{C}$ and cooling from 30 to $15{ }^{\circ} \mathrm{C}$ are in agreement with the laboratory tests as it can be seen in Table 11 . The results present an average of $105.4 \mathrm{Wh}( \pm 44.5 \mathrm{Wh})$ or $4.4 \%( \pm 6.9 \%)$.

Table 11. Thermal load for melting and solidifying.

\begin{tabular}{|c|c|c|c|c|c|c|c|c|c|}
\hline & \multicolumn{4}{|c|}{1 Thermal Battery } & \multicolumn{4}{|c|}{2 Thermal Batteries } & \multirow[b]{3}{*}{$\begin{array}{c}\text { Average } \\
(\sigma)\end{array}$} \\
\hline & \multicolumn{2}{|c|}{ Melting } & \multicolumn{2}{|c|}{ Solidifying } & \multicolumn{2}{|c|}{ Melting } & \multicolumn{2}{|c|}{ Solidifying } & \\
\hline & EP & NP & EP & NP & EP & NP & EP & NP & \\
\hline Laboratory test (Wh) & 831.8 & 1015.8 & -725.6 & -1066.0 & 1472.3 & 2029.1 & -1508.6 & -2336.0 & \\
\hline 3LC (Wh) & 817.5 & 1059.7 & 828.8 & 1074.3 & 1635.0 & 2119.4 & 1657.5 & 2148.6 & \\
\hline Difference (Wh) & -14.3 & 43.9 & 103.2 & 8.4 & 162.7 & 90.4 & 148.9 & -187.4 & $\begin{array}{c}105.4 \\
( \pm 44.5)\end{array}$ \\
\hline Difference & $-1.7 \%$ & $4.3 \%$ & $14.2 \%$ & $0.8 \%$ & $11.1 \%$ & $4.5 \%$ & $9.9 \%$ & $-8.0 \%$ & $\begin{array}{c}9.4 \% \\
( \pm 6.7 \%)\end{array}$ \\
\hline
\end{tabular}

Holding 30\% more material, the new panel needs more time to solidify and melt when compared to the existing panel. Table 12 summarizes the time required and the increase in percentage between new and existing TB.

Table 12. Melting and solidifying times for one and two thermal batteries.

\begin{tabular}{|c|c|c|c|c|}
\hline & & & Time (h) & Increase (in \%) \\
\hline \multirow{4}{*}{$1 \mathrm{~TB}$} & Melting & EP 1TB & 3.5 & \multirow{2}{*}{$86 \%$} \\
\hline & \multirow{3}{*}{ Solidifying } & NP 1TB & 6.5 & \\
\hline & & EP 1TB & 4.0 & \multirow{2}{*}{$38 \%$} \\
\hline & & NP 1TB & 5.5 & \\
\hline \multirow{4}{*}{$2 \mathrm{~TB}$} & Melting & EP 2TB & 4.5 & \multirow{2}{*}{$100 \%$} \\
\hline & IVIelting & NP 2TB & 9.0 & \\
\hline & \multirow{2}{*}{ Solidifying } & EP 2TB & 5.0 & \multirow{2}{*}{$70 \%$} \\
\hline & & NP 2TB & 8.5 & \\
\hline
\end{tabular}

These results can also be seen from the cooling and heating loads. It was compared with a $3 \mathrm{LC}$ test and the results presented a good agreement, indicating an average difference of $105.4 \mathrm{Wh}( \pm 44.5 \mathrm{Wh})$ or $4.4 \%( \pm 6.9 \%)$.

\section{Conclusions}

Researchers have focused their attention to develop new PCMs or assess existing PCM encapsulations in different climates and environmental conditions. However, few of them focused their attention on the heat transfer between panel and air. This is essential to provide a ventilation system which takes advantage of the PCM-air heat transfer to increase its responsiveness.

Focused on five KPIs, those of ease to manufacture, cost of production, rigidity, pressure drop and heat transfer, the present study performed a parametric analysis via CFD simulation. A set of 12 different geometries were analyzed using 3D CFD models to design a panel for a PCM-Air heat exchanger. One geometry and shape was selected as the most effective as it can double the heat transfer of the PCM-air side and holds $13.7 \%$ more PCM material when compared to an existing commercial panel. A further 12 variations and nine configurations were tested using 2D CFD models. The pressure 
drop increased 3.3 times and therefore more power will be necessary to provide the same airflow. However, the heat transfer increase on the PCM-Air side can lead to a reduction in the required airflow.

The selected panel was fabricated and three laboratory tests validated the simulations. The first laboratory test analyzed the heat transfer with different gaps between the panels and Reynolds numbers. For the highest Reynolds number tested (6061), the Nusselt number increased by 124, 72 and 77\%, when compared to the existing panel. For $\operatorname{Re}=4067,94$, 36 and $5 \%$ were found and the most interesting was at a lower Reynolds number (1954). This lower number made the existing panel more efficient when a gap of 9 and $10 \mathrm{~mm}$ was used. A reasonable explanation is that at lower airflows, the protrusions now contribute to increase the heat transfer. When the new and existing panels are compared in terms of the thermal enhancement factor, an increase of $84.4 \%$ was found for an $8 \mathrm{~mm}$ gap and a Reynolds number of 6061 while at $10 \mathrm{~mm}$ and a Reynolds number equals to 1954, the existing panel performs $29.8 \%$ better than the new panel.

The pressure drop was also tested to evaluate if the small fan is capable to provide the same airflow despite the increase in pressure drop. The results were positive with the fan being able to provide the same airflow as the existing panel. In addition, the results agreed with the simulations during the design process.

The third test evaluated the melting and solidifying process. Holding 30\% more material, the new panel needs more time to solidify and melt when compared to the existing panel. These results can also be seen from the cooling and heating load. It was compared with a 3LC test and the results presented an impressive agreement, indicating an average difference of $105.4 \mathrm{Wh}( \pm 44.5 \mathrm{Wh})$ or $4.4 \%( \pm 6.9 \%)$.

The development of a new encapsulation panel for mechanical ventilation systems opens a field of investigation where researchers are able to develop new tools to improve the system. The new PCM panel will also contribute to the industry as it provides a new option of encapsulation for cooling purposes. The flexibility of providing different thicknesses is also a positive characteristic of this panel.

Author Contributions: Conceptualization, T.S., M.K. and L.C.W.; methodology, T.S.; software, T.S. and L.C.W.; validation, T.S. and N.H.; formal analysis, T.S.; investigation, T.S.; resources, N.H.; data curation, T.S.; writing — original draft preparation, T.S. and M.K.; writing—review and editing, M.K., L.C.W. and N.H.; visualization, T.S.; supervision, M.K. and L.C.W.; project administration, M.K.; funding acquisition, T.S. All authors have read and agreed to the published version of the manuscript.

Funding: Thiago Santos would like to thank the Science without Borders program of CNPq-Brazil, for the funding awarded to carry out his PhD at Brunel University London (PDE: 200815/2014-8).

Institutional Review Board Statement: Not applicable.

Informed Consent Statement: Not applicable.

Data Availability Statement: Not applicable.

Acknowledgments: The authors would like to acknowledge support by Kevin Yearley of Monodraught Ltd. for the experimental part of the study and practical advice for the design.

Conflicts of Interest: The authors declare no conflict of interest. The funders had no role in the design of the study; in the collection, analyses, or interpretation of data; in the writing of the manuscript, or in the decision to publish the results. 


\section{Nomenclature}

Symbols

A Area $\left(\mathrm{m}^{2}\right)$

$C_{p(\text { air })} \quad$ Specific heat of air $(\mathrm{J} / \mathrm{kg} \cdot \mathrm{K})$

$D_{h} \quad$ Hydraulic diameter $(\mathrm{m})$

e Ridge height $(\mathrm{m})$

E Sum of gaps (m)

$\mathrm{h} \quad$ Channel gap $(\mathrm{m})$

h Heat convection coefficient $\left(\mathrm{W} / \mathrm{m}^{2}\right)$

$\mathrm{H} \quad$ Total height (m)

$k \quad$ Thermal conductivity $(\mathrm{W} / \mathrm{m} \cdot \mathrm{K})$

L Length (m)

1 Total surface length (m)

im Mass flow $(\mathrm{kg} / \mathrm{s})$

$\mathrm{Nu} \quad$ Nusselt number

$N u_{0} \quad$ Nusselt number over a

$\mathrm{p} \quad$ Pitch (m)

$\dot{Q} \quad$ Heat Flux (W)

Re Reynolds number

$\mathrm{r} \quad$ Ridge radius (m)

$\mathrm{s} \quad$ Ridge spacing $(\mathrm{m})$

$\mathrm{T}$ temperature $\left({ }^{\circ} \mathrm{C}\right)$

$T_{t} \quad$ Sum of panel thickness (m)

W Width (m)

$\begin{array}{ll}\begin{array}{ll}\text { Subscripts } \\ \text { air }\end{array} & \\ i & \text { Inlet } \\ m & \text { Fluid } \\ o & \text { Outlet } \\ s & \text { Surface }\end{array}$

Greek symbols $\eta$ $\Delta p$

$\Delta p_{0}$

$\Delta \mathrm{T}$

Abbreviations

CCD

CFD

PCM

KPI

LMDT

TB

TEF

TES

3LC
Efficiency

Pressure difference $(\mathrm{Pa})$

$\Delta p$ of a smooth surface $(\mathrm{Pa})$

Temperature difference $(\mathrm{K})$

Charged Coupled Device

Computational Fluid Dynamics

Phase Change Material

Key Performance Indicator

Log Mean Difference Temperature

Thermal Battery

Thermal Enhancement Factor

Thermal Storage System

Three Layer Calorimeter

\section{References}

1. Arzamendia Lopez, J.P.; Kuznik, F.; Baillis, D.; Virgone, J. Numerical modeling and experimental validation of a PCM to air heat exchanger. Energy Build. 2013, 64, 415-422. [CrossRef]

2. Zalba, B.; Marín, J.M.; Cabeza, L.F.; Mehling, H. Free-cooling of buildings with phase change materials. Int. J. Refrig. 2004, 27, 839-849. [CrossRef]

3. Dolado, P.; Lazaro, A.; Marin, J.M.; Zalba, B. Characterization of melting and solidification in a real-scale PCM-air heat exchanger: Experimental results and empirical model. Renew. Energy 2011, 36, 2906-2917. [CrossRef]

4. Lazaro, A.; Dolado, P.; Marín, J.M.; Zalba, B. PCM-air heat exchangers for free-cooling applications in buildings: Experimental results of two real-scale prototypes. Energy Convers. Manag. 2009, 50, 439-443. [CrossRef]

5. Alizadeh, M.; Sadrameli, S.M. Development of free cooling based ventilation technology for buildings: Thermal energy storage (TES) unit, performance enhancement techniques and design considerations-A review. Renew. Sustain. Energy Rev. 2016, 58, 619-645. [CrossRef]

6. Santos, T.; Hopper, N.; Kolokotroni, M. Performance in practice of a ventilation system with thermal storage in a computer seminar room. In Proceedings of the CLIMA 2016, 12th CLIMA REHVA World Congress, Aalborg, Denmark, 22-25 May 2016.

7. Kolokotroni, M.; Santos, T.; Hopper, N. Ventilative cooling of a seminar room using active PCM thermal storage. REHVA 2016, 53, 36-40.

8. Santos, T.; Kolokotroni, M.; Hopper, N.; Yearley, K. A study of panel ridges effect on heat transfer and pressure drop in a ventilation duct. In Proceedings of the 38th AIVC-6th TightVent \& 4th venticool Conference, Nottingham, UK, 13-14 September 2017.

9. Moon, M.A.; Park, M.J.; Kim, K.Y. Evaluation of heat transfer performances of various rib shapes. Int. J. Heat Mass Transf. 2014, 71, 275-284. [CrossRef]

10. Yang, W.; Xue, S.; He, Y.; Li, W. Experimental study on the heat transfer characteristics of high blockage ribs channel. Exp. Therm. Fluid Sci. 2017, 83, 248-259. [CrossRef]

11. Tanda, G. Heat transfer in rectangular channels with transverse and V-shaped broken ribs. Int. J. Heat Mass Transf. 2004, 47, 229-243. [CrossRef]

12. Kim, K.M.; Lee, H.; Kim, B.S.; Shin, S.; Lee, D.H.; Cho, H.H. Optimal design of angled rib turbulators in a cooling channel. Heat Mass Transf. Stoffuebertragung 2009, 45, 1617-1625. [CrossRef]

13. Zhang, F.; Wang, X.; Li, J. Flow and heat transfer characteristics in rectangular channels using combination of convex-dimples with grooves. Appl. Therm. Eng. 2017, 113, 926-936. [CrossRef]

14. Promvonge, P.; Thianpong, C. Thermal performance assessment of turbulent channel flows over different shaped ribs. Int. Commun. Heat Mass Transf. 2008, 35, 1327-1334. [CrossRef] 
15. Thianpong, C.; Chompookham, T.; Skullong, S.; Promvonge, P. Thermal characterization of turbulent flow in a channel with isosceles triangular ribs. Int. Commun. Heat Mass Transf. 2009, 36, 712-717. [CrossRef]

16. Promvonge, P.; Chompookham, T.; Kwankaomeng, S.; Thianpong, C. Enhanced heat transfer in a triangular ribbed channel with longitudinal vortex generators. Energy Convers. Manag. 2010, 51, 1242-1249. [CrossRef]

17. Iten, M.; Liu, S.; Shukla, A. A review on the air-PCM-TES application for free cooling and heating in the buildings. Renew. Sustain. Energy Rev. 2016, 61, 175-186. [CrossRef]

18. Choi, E.Y.; Choi, Y.D.; Lee, W.S.; Chung, J.T.; Kwak, J.S. Heat transfer augmentation using a rib-dimple compound cooling technique. Appl. Therm. Eng. 2013, 51, 435-441. [CrossRef]

19. Ligrani, P.M.; Mahmood, G.I.; Harrison, J.L.; Clayton, C.M.; Nelson, D.L. Flow structure and local Nusselt number variations in a channel with dimples and protrusions on opposite walls. Int. J. Heat Mass Transf. 2001, 44, 4413-4425. [CrossRef]

20. SriHarsha, V.; Prabhu, S.V.; Vedula, R.P. Influence of rib height on the local heat transfer distribution and pressure drop in a square channel with $90^{\circ}$ continuous and $60^{\circ}$ V-broken ribs. Appl. Therm. Eng. 2009, 29, 2444-2459. [CrossRef]

21. Liou, T.M.; Chang, S.W.; Huang, C.Y.; Chan, S.P.; Lan, Y.A. Particle image velocimetry and infrared thermography measurements in a two-pass 90-deg ribbed parallelogram channel. Int. J. Heat Mass Transf. 2016, 93, 1175-1189. [CrossRef]

22. Liu, J.; Song, Y.; Xie, G.; Sunden, B. Numerical modeling flow and heat transfer in dimpled cooling channels with secondary hemispherical protrusions. Energy 2015, 79, 1-19. [CrossRef]

23. Hwang, S.D.; Kwon, H.G.; Cho, H.H. Local heat transfer and thermal performance on periodically dimple-protrusion patterned walls for compact heat exchangers. Energy 2010, 35, 5357-5364. [CrossRef]

24. ASHRAE. ASHRAE Fundamentals, SI ed.; ASHRAE: Atlanta, GA, USA, 2013; Volume 1, ISBN 9781933742557.

25. Incropera, F.P. Fundamentals of Heat and Mass Transfer; John Wiley: Hoboken, NJ, USA, 2007; ISBN 0471457280.

26. Tyagi, K.; Singh, P.; Pandit, J.; Ramesh, S.; Ekkad, S.V.; Tolpadi, A. Experimental study of heat transfer augmentation in high aspect-ratio channels featuring different dimple configurations. In Proceedings of the ASME Turbo Expo 2015: Turbine Technical Conference and Exposition, Montreal, QC, Canada, 15-19 June 2015; pp. 1-11.

27. HTM F Hybrid Ventilation. Available online: https://www.monodraught.com/products/hybrid-ventilation/htm- $\mathrm{f}$ (accessed on 8 January 2021).

28. CrodaTherm ${ }^{\mathrm{TM}}$ Bio-based Phase Change Materials | Croda Phase Change Materials. Available online: https://www.crodatherm. com/en-gb (accessed on 8 January 2021).

29. Moffat, R.J. Describing the uncertainties in experimental results. Exp. Therm. Fluid Sci. 1988, 1, 3-17. [CrossRef]

30. Zhang, Z.; Zhang, W.; Zhai, Z.J.; Chen, Q.Y. Evaluation of Various Turbulence Models in Predicting Airflow and Turbulence in Enclosed Environments by CFD: Part 2-Comparison with Experimental Data from Literature. HVAC R Res. 2007, 13, 871-886. 